\title{
The emergence of Liu Kang's new painting style (1950-1958): a multi-analytical approach for the study of the artist's painting materials and technique
}

\author{
Damian Lizun ${ }^{1 *} \mathbb{0}$, Teresa Kurkiewicz², Mateusz Mądry ${ }^{3}$ and Bogusław Szczupak ${ }^{3}$
}

\begin{abstract}
Liu Kang (1911-2004) was renowned Singapore artist trained in Shanghai and Paris, and known for his contributions to the Nanyang style - an art movement practised by migrant Chinese painters in Singapore between the late 1940s to the 1960s. The style depicts aspects of the tropical way of life, synthetising the artistic traditions of the School of Paris and Chinese ink painting with remarkable stylistic innovations. The aim of this study was to characterise Liu Kang's painting materials and technique by way of ten paintings from a significant period in his oeuvre, 1950-1958, during which his Nanyang style emerged. The selected artworks are from the National Gallery Singapore. A broad range of analytical techniques was employed to study the painting supports and paint layers. The results indicate the prevailing use of commercially prepared linen canvases with double-layered oil-based ground. Single- and triplelayered structures of the ground, as well as semi-absorbent ground, were used sporadically. The identified group of pigments partially overlaps with those already known from Liu Kang's earlier practice and also incorporates some noteworthy peculiarities like manganese, cerulean and phthalocyanine blues, phthalocyanine green, zinc yellow, and naphthol red AS-D. Some of these newly identified pigments made a distinctive appearance in the individual artworks, but ultimately Liu Kang was not convinced about increasing their role in his painting practice of the 1950s as presented in this research. This study highlights the significance of drawing and photography as integral elements of his artistic process. It also delves into the artist's different painting approaches and discusses their evolution, which culminated in the stylistic innovation that became Liu Kang's signature for decades to come. The obtained data may assist art historians and conservators in authenticity and attribution studies, evaluating the condition of artworks and designing conservation strategies. Moreover, this study contributes to the growing body of knowledge about twentieth-century artists' materials, which are characterised by the complex mixtures of inorganic and organic compounds. It also provides information about the availability of art materials in Singapore in the 1950s.
\end{abstract}

Keywords: Liu Kang, Pigment identification, Hidden paintings, SEM-EDS, FTIR, IRFC, X-RAY, RTI

\footnotetext{
*Correspondence: damian_lizun@nhb.gov.sg; d.lizun@fineartconservation.ie ${ }^{1}$ Heritage Conservation Centre, National Heritage Board, 32 Jurong Port $\mathrm{Rd}, 619104$ Singapore, Republic of Singapore

Full list of author information is available at the end of the article
}

\begin{abstract}
Introduction
Liu Kang (1911-2004) was one of the most eminent painters of modern art in Singapore. Following his graduation from Xinhua Arts Academy in Shanghai in 1928, he moved to Paris where his career gained momentum and was marked by a highly creative period from 1929 to 1932. During that time, the artist studied at the Académie de la Grande Chaumière in Montparnasse and
\end{abstract}

Springer Open

(c) The Author(s) 2022. Open Access This article is licensed under a Creative Commons Attribution 4.0 International License, which permits use, sharing, adaptation, distribution and reproduction in any medium or format, as long as you give appropriate credit to the original author(s) and the source, provide a link to the Creative Commons licence, and indicate if changes were made. The images or other third party material in this article are included in the article's Creative Commons licence, unless indicated otherwise in a credit line to the material. If material is not included in the article's Creative Commons licence and your intended use is not permitted by statutory regulation or exceeds the permitted use, you will need to obtain permission directly from the copyright holder. To view a copy of this licence, visit http://creativecommons.org/licenses/by/4.0/. The Creative Commons Public Domain Dedication waiver (http://creativeco mmons.org/publicdomain/zero/1.0/) applies to the data made available in this article, unless otherwise stated in a credit line to the data. 
painted intensively in an attempt to assimilate the artistic essence of the Western masters. In 1933, he accepted the post of Professor at the Shanghai Art Academy and focused on teaching and painting. The heretofore rapid artistic development was impacted by his decision to emigrate to Malaya in 1937 due to the Second SinoJapanese War (1937-1945). After the war, in 1945, Liu Kang permanently relocated to Singapore. He continued painting, mainly during trips across Malaya. His painting style began to evolve, showing less resemblance to the Post-Impressionist mode from the Paris and Shanghai periods; this suggests an attempt to develop a personal painting style [1]. However, it was only in the 1950s that he formulated his pivotal painting concepts, which furthered his artistic career. Following in the footsteps of the Belgian artist Adrien-Jean Le Mayeur de Merpres and inspired by the French Post-Impressionist artist Paul Gauguin, Liu Kang embarked on a month-long painting journey to Indonesia in 1952 with fellow painters Cheong Soo Pieng, Chen Wen Hsi and Chen Chong Swee, who were also Chinese emigrants to Singapore. In particular, the trip to the Indonesian island of Bali inspired them to establish the artistic concept known as the Nanyang style, and was a turning point in their artistic development.

The term "Nanyang" in the Chinese language means "Southern Seas", referring to the geographical area situated south of mainland China, known today as Southeast Asia [2]. The Nanyang style is associated with paintings that express a consciousness of regional identity amongst the migrant Chinese painters in Singapore, stemming from an erosion of ties with China, especially after the start of communist rule in 1949 [3]. The painting style reflects an eclectic amalgamation of two artistic traditions, the School of Paris and Chinese ink painting [4-6], representing Southeast Asian subject matter. However, according to some scholars, a formal description of the Nanyang style remains elusive as it did not evolve into a coherent art movement with an agreed manifesto [5-7]. Thus, the common denominator among the Nanyang style artists was Nanyang, the geographical locality to which the artworks are related [8]. Artists also responded to the founder of Singapore's Nanyang Academy of Fine Arts (NAFA) Lim Hak Tai's call for art that embodies the tropical sensibility and complex ethnic consciousness of the region, and is, concurrently, socially engaged [9, 10]. Artists selected their own artistic languages to represent local subjects and evoke local sentiments. Thus, Liu Kang reflected retrospectively in 1997: "In my opinion it [Nanyang style painting] should consist of these components: One, the subject matter must be of Nanyang (the South Seas). Generally, this would include the tropical region, $[. .$.$] confined only to scenes of nature$ and social activities. Highly modernised and industrialised regions and prosperous commercial areas would not make this category. Two, technique and expression. The Nanyang artist expresses in a subjective manner, utilising technical expression that would, in a simple, plain and lyrical manner, depict the natural or human landscapes of Nanyang. Excessive objectivity and unimaginative depictions should be avoided. Three, style and tone. The use of bright and cheery light and colours should be maximised and co-ordinated with brushstrokes and lines that are fluid yet steady." [11].

Although Liu Kang stated that an accurate representation of the Nanyang style should exclude modern aspects of life, his artworks from the 1950s show that he did not restrict the subject matter. Besides the expression of a local tropical flavour, his paintings frequently depicted urban activities and scenes of street hawkers in the immediate surroundings $[4,12]$. Although these scenes do not evoke the idyllic lifestyle [13], they could be a response to Lim Hak Tai's call for social engagement of Nanyang art $[9,14]$. Another reason for depicting modern life in the paintings could be poor accessibility to the Malayan countryside as well as movement restrictions imposed on the local communities by the British Administration due to the threat of communist insurgency [12].

In an attempt to depict Nanyang style, Liu Kang integrated Western painting techniques with Chinese traditional ink painting, the latter representing his cultural inheritance. Along with these two art traditions, a remarkable stylistic innovation in the form of a batikinspired painting technique also emerged, characterised by unpainted outlines of objects and figures.

Liu Kang has been recognised as one of the most famous Nanyang artists, and extensive literature has been devoted to discussing the roots of the Nanyang style. However, no comprehensive study of Liu Kang's painting practice from the 1950s, when the style emerged, has been carried out. Hence, this study focuses on the investigation of the painting supports, pigments and techniques Liu Kang used in his early Nanyang style paintings. The collected data may be useful to scholars who wish to further explore the art of Liu Kang and to conservators in charge of his works, which reveal the rapid evolution of the technique. The interest in Liu Kang's painting process extends beyond Singapore and Southeast Asia as the artist bridged Western and Eastern artistic trends and relied on the materials imported from overseas. Hence, this study adds to the existing international research of twentieth-century artists' materials, which are characterised by the complex mixtures of inorganic and organic compounds. Moreover, this research points out some art supplies in Singapore in the 1950s, and hence contributes to the knowledge of their distribution and accessibility. 
This study is a part of an ongoing research that aims to present the painted oeuvre of Liu Kang and the emergence of his early Nanyang style as the next breakthrough after the Paris and Shanghai periods, which were investigated earlier by the authors $[15,16]$.

\section{Research materials Paintings}

The focus of this study is the collection of ten paintings by Liu Kang from the National Gallery Singapore (NGS), spanning the important period in the emergence of the Nanyang style (1950-1958) (Figs. 1, 2). The selection of artworks was guided by the range of painting techniques by which they were executed, thus providing a unique opportunity for investigating their technical and stylistic evolution. Thus, the research base includes the paintings created shortly before the well-known trip to IndonesiaVillage (1950) and Kampong scene (1951). They show a stylistic relationship with the paintings created after 1952 in their depiction of lush tropical landscapes as well as the daily life of people from different ethnic groups [17]. The study involves the characterisation of the painting supports and paint layers.

\section{Samples}

The research material also consisted of 82 samples of the paint material and seven XRF spot measurements collected from the artworks (Figs. 1, 2). Additionally, 20 samples of fibres were extracted from the threads of weft and warp of each textile painting support for the identification.

\section{Research methods}

The applied analytical methods for studying the painting materials and the artist's technique included both non- and micro-invasive techniques. As an informative first-step approach, a technical description of the artworks was made. Then, digital microscopy was engaged to obtain information about the structure of the textile supports, such as weave, density and twist of threads. Next, technical photography comprising visible light (VIS), ultraviolet fluorescence (UVF), reflected ultraviolet (UVR) and infrared (IR) was conducted to tentatively identify the pigments and select the sampling areas. Reflectance transformation imaging (RTI) and surface digital microscopy were used to study the texture of the paintings and collect evidence of the underlying compositions, which were later visualised with IR and X-ray radiography (XRR). The following step involved sampling from the areas of the existing paint losses. Then, analyses of the collected material were carried out with optical microscopy (OM), polarised light microscopy (PLM) and field emission scanning electron microscope with energy dispersive spectroscopy (FE-SEM-EDS). These techniques allowed us to characterise the structure and constituents of the ground layers and paint mixtures. The indication of the organic and inorganic components was given by attenuated total reflectance-Fourier transform infrared spectroscopy (ATR-FTIR) as a supplementary technique. The morphology of the textiles' fibres and the results of the chemical staining tests were studied using $\mathrm{OM}$. The results obtained through the analytical methods were cross-referenced with a variety of archival sources.

\section{Technical photography}

Technical photography was performed according to the workflow proposed by Cosentino [18-20] with a fullspectrum (360-1100 nm) modified Nikon 850 DSLR camera equipped with a Nikon AF Micro NIKKOR $60 \mathrm{~mm} \mathrm{f} / 2.8 \mathrm{D}$ lens. The camera was calibrated with $\mathrm{X}$-Rite ColorChecker Passport. The American Institute of Conservation Photo Documentation (AIC PhD) target was used to adjust the white balance and exposure of the RAW format images.

VIS photography illumination was provided by two $500 \mathrm{~W}$ halogen lamps. X-Nite CC1 and B+W 415 filters were coupled together and placed in front of the camera lens for VIS imaging. The same set of filters was used for the UVF imaging with the illumination system consisting of two lamps equipped with eight $40 \mathrm{~W} 365 \mathrm{~nm}$ UV fluorescence tubes. UVR photography was achieved using the same lighting conditions as for the UVF and Andrea "U" MK II filter was used on the lens. IR imaging, with an additional objective of false-colour infrared imaging (IRFC), was performed using the same illumination system as for VIS, and a Heliopan RG1000 filter was mounted on the camera lens.

Further processing of the images, including IRFC manipulation, was conducted using Adobe Photoshop $\mathrm{CC}$ according to the standards described by the American Institute of Conservation [21].

\section{High-resolution digital microscopy}

Digital microscope images of the recto and verso of the paintings were taken with Keyence VHX-6000, using a zoom lens coupled with a high-speed camera. Observations were conducted at magnifications of $\times 20$ to $\times 200$. For measurement analyses, built-in Keyence softwareVHX-H2M2 and VHX-H4M-was used.

\section{RTI}

RTI was carried out following the workflow proposed by Cultural Heritage Imaging [22]. The captured images were processed using Adobe Photoshop CC and RTIBuilder. The results were visualised through RTIViewer 

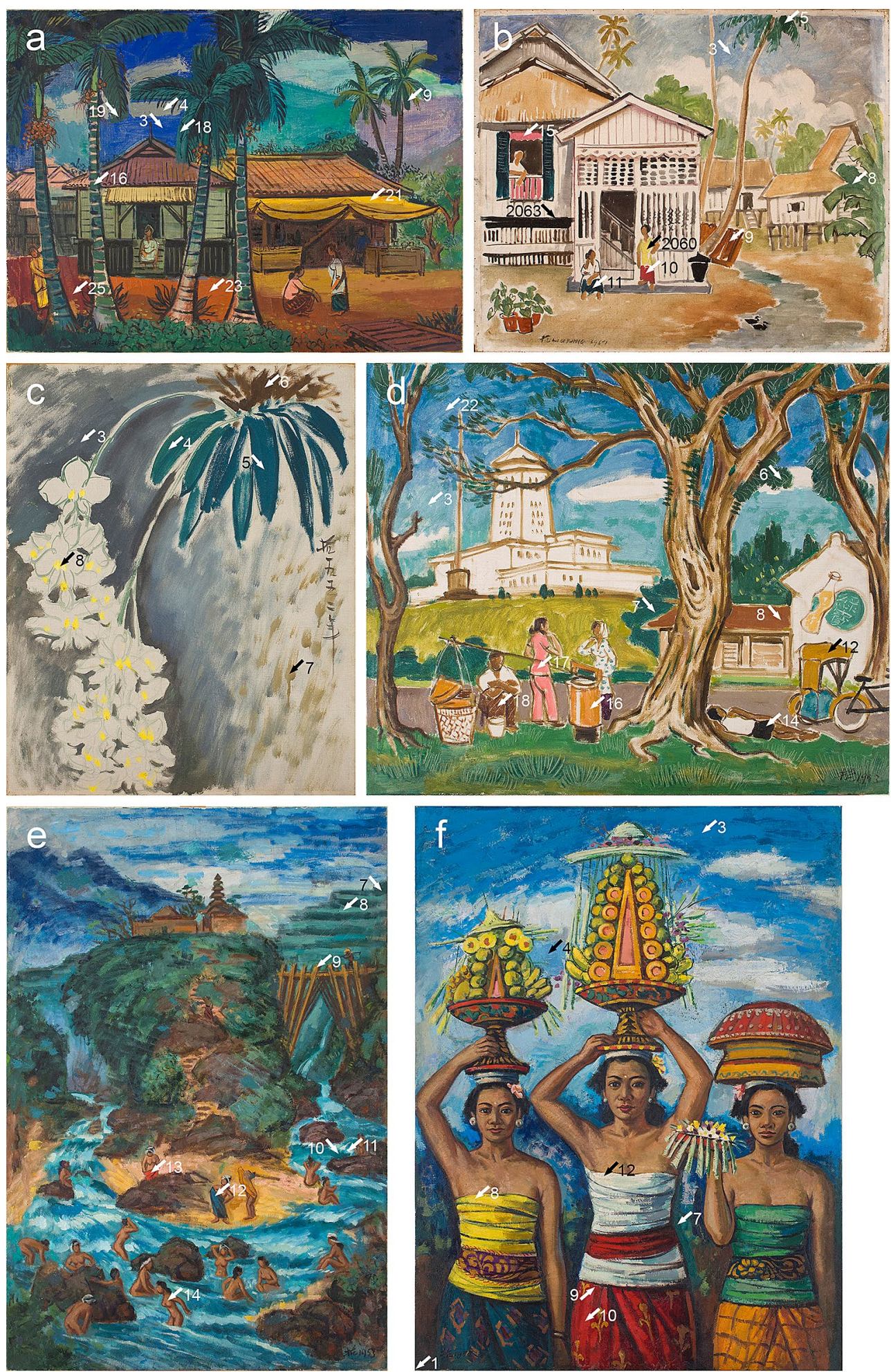

Fig. 1 The paintings by Liu Kang: a Village, 1950, oil on canvas, $99 \times 131.5 \mathrm{~cm}$; b Kampong scene, 1951, oil on canvas, $60 \times 72.5 \mathrm{~cm} ; \mathbf{c}$ Orchids, 1952, oil on canvas, $50 \times 40.5 \mathrm{~cm}$; d Government office in Johore Bahru, 1953, oil on canvas, $63.2 \times 76.3 \mathrm{~cm}$; e Scene in Bali, 1953, oil on canvas, $127 \times 85.5 \mathrm{~cm} ; \mathbf{f}$ Offerings, 1953, oil on canvas, $131.5 \times 98.5 \mathrm{~cm}$. Gifts of the artist's family. Collection of National Gallery Singapore. White arrows indicate sampling areas 

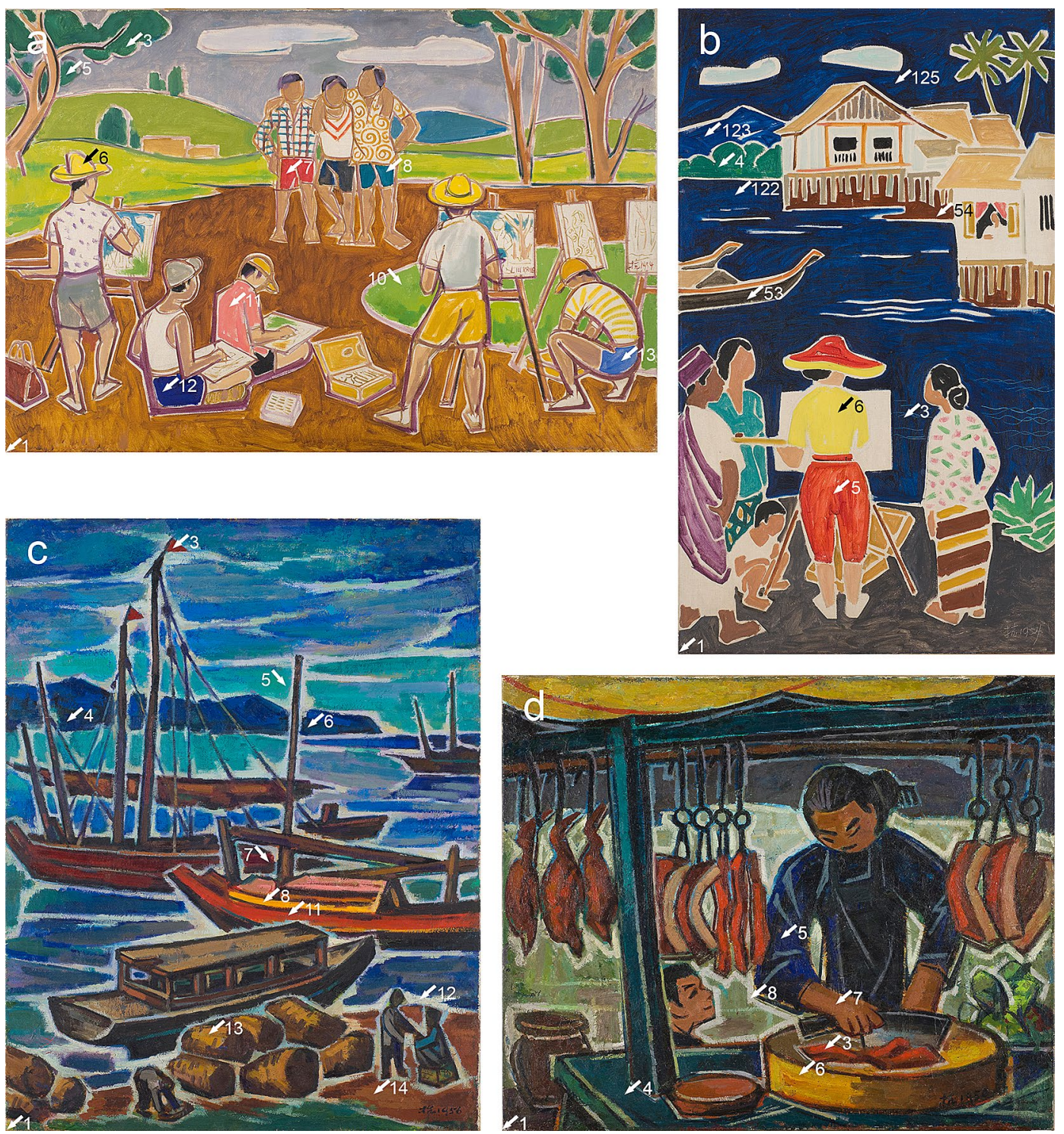

Fig. 2 The paintings by Liu Kang: a Outdoor painting, 1954, oil on canvas, $85 \times 127 \mathrm{~cm}$; b Painting kampong, 1954, oil on canvas, $120.5 \times 71 \mathrm{~cm}$; c Boats, 1956, oil on canvas, $91 \times 70 \mathrm{~cm}$; d Char Siew seller, 1958, oil on canvas, $59.5 \times 72.5 \mathrm{~cm}$. Gifts of the artist's family. Collection of National Gallery Singapore. White arrows indicate sampling areas

software, as proposed by Cultural Heritage Imaging [23, 24].

\section{XRR}

Paintings were X-ray radiographed with a Siemens Ysio Max digital system with a detector of dimensions $35 \times 43 \mathrm{~cm}$ and a resolution of 7 million pixels. The X-ray tube operated at $40 \mathrm{kV}$ and $0.5-2 \mathrm{mAs}$. The radiographic images were visualised and processed using dedicated $\mathrm{X}$-ray medical imaging software, iQ-LITE, then exported to Adobe Photoshop CC for final alignment and merging.

\section{$X R F$}

XRF measurements were performed using Thermo Scientific $^{\mathrm{TM}}$ Niton $^{\mathrm{TM}}$ XL3t 970 portable spectrometer with a GOLDD+ detector and an Ag anode X-ray tube with a $6-50 \mathrm{kV}$ voltage and up to $0.2 \mathrm{~mA}$ current. A mining mode with four elemental ranges and a measurement duration of $50 \mathrm{~s}$ each (total acquisition time of $200 \mathrm{~s}$ ) were used to better differentiate the light elements from the heavy ones. The spectra were obtained at a working distance of $1 \mathrm{~mm}$ and an analytical spot diameter of $3 \mathrm{~mm}$. The spectra were processed with Thermo Scientific $^{\mathrm{TM}}$ Niton Data Transfer $\left(\mathrm{NDT}^{\mathrm{TM}}\right.$ ) 8.4.3 software. 


\section{OM and PLM}

The paint samples' structure was examined in reflected VIS and UV light on a Leica DMRX polarised microscope providing $\times 100, \times 200$, and $\times 400$ magnifications. PLM of the pigments and morphology of the fibres were carried out in transmitted VIS light at the same range of magnifications. PLM of the pigments was conducted according to the workflow developed by Peter and Ann Mactaggart [25]. The samples were digitally photographed using a Leica DFC295 camera.

\section{Staining tests}

The phloroglucinol stain test was carried out on the natural fibres to determine the presence and concentration of lignin [26].

\section{FE-SEM-EDS}

The paint samples' cross-sections were mounted on carbon tapes and analysed with a Hitachi SU5000 FESEM coupled with Bruker XFlash ${ }^{\circledR}$ 6/60 EDS. The SEM, backscattered electron mode (BSE), was operated at an accelerating voltage of $20 \mathrm{kV}, 60 \mathrm{~Pa}$ chamber pressure, 50-60 intensity spot and $180 \mathrm{~s}$ acquisition time. Analyses were conducted at a working distance of $10 \mathrm{~mm}$. The data collection and processing were performed with Bruker ESPIRIT 2.0 software.

\section{ATR-FTIR}

ATR-FTIR analyses were performed using a Bruker Hyperion 3000 FTIR microscope equipped with a midband MCT detector, coupled with a Vertex 80 FTIR spectrometer. The spectra were acquired in the spectral range of $4000-600 \mathrm{~cm}^{-1}$ and resolution of $4 \mathrm{~cm}^{-1}$. A total of 64 scans were recorded for each sample. Spectra collection and processing were carried out using Bruker Opus 7.5 software. The interpretation of data was performed using the reference spectra in the material collection of the Institute for Conservation, Restoration and Study of Cultural Heritage, Nicolaus Copernicus University, as well as spectral library of the Infrared and Raman Users Group (IRUG) [27].

\section{Preparation of samples}

Selected paint samples were prepared as cross-sections by mounting in acrylic resin-ClaroCit from Struers (USA). The PLM pigment scrapings were prepared as dispersions on microscope slides in a mounting medium Meltmount from Cargille (USA) with a refractive index of 1.662, and covered with a cover glass. The samples of fibres were immersed in a boiled water to soften and clean off contaminants. Then, they were mounted on microscope slides with a drop of water under the cover glass.

\section{Archival sources}

Although to the best knowledge of authors, the information about the brands of the paints used by Liu Kang in the 1950 s is non-existent, the local newspapers', magazines' and trade directories' advertisements from the period under investigation provided background information about the availability of the art materials in Singapore. Based on the advertisements, contemporary colourmen catalogues, such as Rowney from 1951 and 1955, Winsor \& Newton (W\&N) from 1955 and 1957, and Reeves \& Sons (R\&S) from 1958, were referenced to expand the discussion about the possible use of certain materials that were identified in the investigated paintings. However, conclusions about the brands of materials used by the artist should not be hastily drawn. The authors came across only one source that listed some commercial names of the paints used by Liu Kang in 1955 , and this information is cross-referenced with the data acquired from the analysed paint mixtures. Old photographs and the artist's drawings from the Liu family archives were invaluable for understanding the artist's approach to painting.

\section{Results and discussion Auxiliary supports}

Of the ten examined paintings, nine are stretched over bevelled strainers and one is stretched over plywood board. The paintings are mounted through the tacking margins with steel staples. Additionally, the observation of the tacking margins revealed a presence of empty nail holes, which do not correspond to the holes in the auxiliary supports. This allowed us to infer that the auxiliary supports are not original and that the nail holes could correspond to the original mounting method. Judging by the absence of original auxiliary supports, one can guess that they were of poor quality and were likely to have been made locally. The inventory and technical data of the paintings are summarised in Table 1 .

\section{Fabric types}

All investigated paintings were executed on plain-weave canvases made of Z-twisted threads of weft and warp. Linen fibres were identified by their morphology features, such as transverse markings and dislocations, as well as uneven pink stains obtained by the phloroglucinol test [26].

Four weave matching groups were determined. Group 1 is represented by one canvas with a thread count approximating $14 \times 17$ per $\mathrm{cm}$. Group 2 is the most dominant and is characterised by a consistent thread count 
Table 1 Inventory and technical details of the investigated paintings

\begin{tabular}{llllll}
\hline Title \& inventory number & Date & Dimensions $\mathbf{H} \times \mathbf{W} \mathbf{( \mathbf { c m } )}$ & Orientation & $\begin{array}{l}\text { Type of auxiliary support } \\
\text { strainer/stretcher/rigid support }\end{array}$ & $\begin{array}{l}\text { Painted on } \\
\text { an earlier } \\
\text { composition }\end{array}$ \\
\hline Village, 2003-03270 & 1950 & $99 \times 131.5$ & Horizontal & Strainer & No \\
Kampong scene, 2003-03245 & 1951 & $60 \times 72.5$ & Horizontal & Strainer & No \\
Orchids, 2003-03379 & 1952 & $50 \times 40.5$ & Vertical & Plywood board & No \\
Government Office in Johore & 1953 & $63.2 \times 76.3$ & Horizontal & Strainer & No \\
$\begin{array}{l}\text { Bahru, 2003-03300 } \\
\text { Scene in Bali, 2003-03333 }\end{array}$ & 1953 & $127 \times 85.5$ & Vertical & Strainer & Yes \\
Offerings, 2003-03269 & 1953 & $131.5 \times 98.5$ & Vertical & Strainer & Yes \\
Outdoor painting, 2003-03290 & 1954 & $85 \times 127$ & Horizontal & Strainer & No \\
Painting kampong, 2003-04149 & 1954 & $120.5 \times 71$ & Vertical & Strainer & No \\
Boats, 2003-03275 & 1956 & $91 \times 70$ & Vertical & Strainer & Yes \\
Char Siew seller, 2003-03311 & 1958 & $59.5 \times 72.5$ & Horizontal & Strainer & Yes
\end{tabular}

of $13 \times 15$ per $\mathrm{cm}$. It was found in six paintings. Group 3 comprises two denser canvases with a thread count of $16 \times 17 \mathrm{~cm}$. Group 4, with a thread count of $11 \times 10$ per $\mathrm{cm}$, was identified in one painting (Fig. 3).

\section{Characteristics of the grounds}

All examined paintings have white and textured ground extended over the tacking margins, indicating a commercial preparation of the canvases. Analyses of the structure and composition of the ground layers allowed us to identify five types of preparation of the canvases.

The ground of type 1 is double-layered, and it was found in Village (sample 9). The bottom layer is homogenous and predominantly composed of lead white (PW1) mixed with lithopone (PW5) and/or barium white (PW21) and zinc white (PW4), and some titanium white (PW6) (Fig. 4a, b). The top layer is composed of the same constituents as the bottom layer but with an abundance of titanium white. A drying oil as a binder was confirmed with FTIR in both layers by peaks at 2933, 2852 (both $\mathrm{C}-\mathrm{H}$ stretching bands), 1728 ( $\mathrm{C}=\mathrm{O}$ stretching band), 1432, 1238, 1161 and $723 \mathrm{~cm}^{-1}$ [28].

The ground of type 2 is predominant and was identified in five paintings. It has a double-layered structure with a bottom layer that is usually thicker than the top. Both layers are composed of the same ingredients but mixed in different concentrations. Thus, the bottom layer is characterised by large particles of chalk (PW18) and clumps of lead white admixed with lithopone and/or barium white and zinc white. The top layer is formed mainly from lead white well mixed with lithopone and/or barium white and zinc white, some chalk and titanium white (Fig. 4c, d). A drying oil was positively identified in both layers with FTIR by peaks at around 2956, 2918, 2850, 1732, 1240, 1180 and $720 \mathrm{~cm}^{-1}$. Additionally, zinc soaps were evident in three samples of the ground layer by a typical infrared peak at $1540 \mathrm{~cm}^{-1}$ corresponding to $\mathrm{COO}^{-}$asymmetric stretching band [29-31].

The morphology of the ground of type 3 is characterised by a single and homogenous layer of zinc white (Fig. 4e, f). This type of ground was detected in two paintings: Outdoor painting (sample 1) and Painting kampong (sample 1). FTIR spectra showed drying oil binder by peaks at 2956, 2918, 2849, 1732, 1460, 1376, 1242, 1165 and $722 \mathrm{~cm}^{-1}$, and zinc soaps formation by typical IR absorption at $1541 \mathrm{~cm}^{-1}$.

The ground of type 4 is single-layered and predominantly composed of poorly ground particles of lead white (Fig. 4g, h). Trace amounts of $\mathrm{Ca}$ and Ba suggest an admixture of chalk and barium white; however, the latter was not detected with FTIR. A presence of drying oil confirmed with FTIR by peaks at 2957, 2924, 2851, 1729, $1240,1160,1100$ and $710 \mathrm{~cm}^{-1}$, and proteins indicated by signals recorded at 1639 (amide I) and $1517 \mathrm{~cm}^{-1}$ (amide II) allowed us to infer a semi-absorbent emulsion of oil and animal glue binders. This kind of ground layer composition was identified in Offerings (sample 1).

The ground of type 5 was determined by the triplelayered structure. The upper layer is thin and the elements identified are attributable to titanium white, lithopone and/or barium white and zinc white, as well as lead white and chalk. However, the structure and composition of the bottom and middle layers strongly resemble the ground of type 2 (Fig. $4 \mathrm{i}, \mathrm{j}$ ). Considering that this type of ground was found only in one painting, it seems reasonable to conclude that the ground layer was originally of type 2 and later modified by the artist by the application of a thin coat of white paint containing mainly titanium white. 

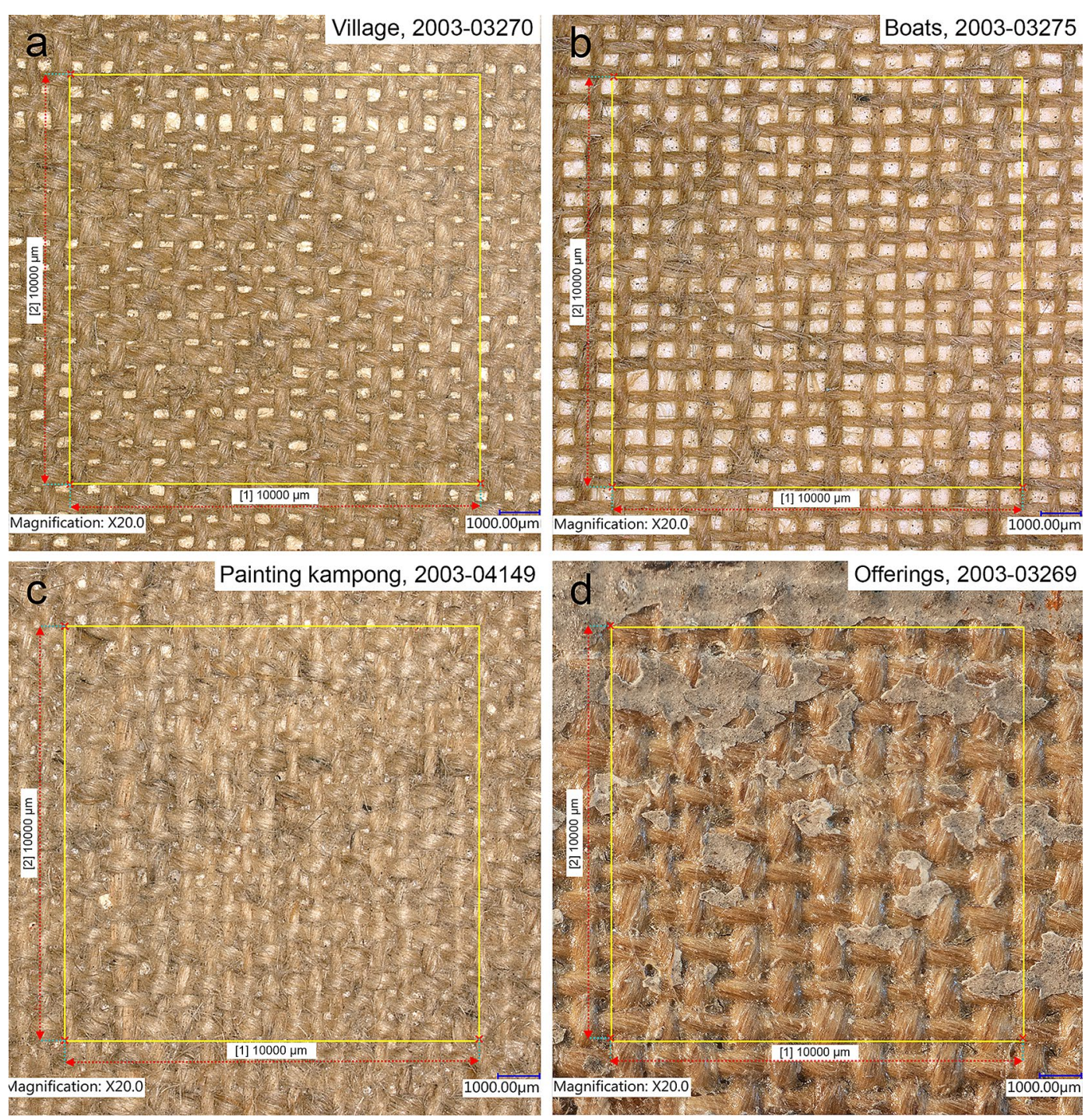

Fig. 3 Photomicrographs of four weave matching groups identified in the investigated paintings: a group 1; b group 2; c group 3; d group 4

The acquired data allowed us to find a notable correlation between the structure of the grounds and the canvases. Thus, the canvas and ground of type 1 were found only in Village. Interestingly, two similar stamps were found on the reverse side of this painting. Despite the poor legibility of the print, the IR enhanced photography suggests that the stamps show a capital $S$, a painting brush and the word "CANVAS" above (Fig. 5). The presence of the stamps may suggest that the canvas for Village was commercially prepared and stretched. Unfortunately, the authors could not attribute the stamps to any colourmen known to them.

In the 1950s, the art materials were available in Singapore from the specialised retailer The Straits Commercial $[32,33]$, as well as from stationery and book shops, such as E. J. Motiwalla \& Co. and The Shanghai Book Co., Ltd. $[34,35]$. However, it is unknown what specific brands the shops had distributed at that time (Fig. 6a-c). The 1947 and 1948 advertisements of the two latter companies inform that they imported R\&S and W\&N brands [36]. Moreover, according to the 1955 advertisement, the art materials from the Dutch company Talens were imported by Jacobson van den Berg Ltd (Fig. 6d) [37]. There is also a possibility that other overseas brands of artist materials were available in Singapore as the city enjoyed a free trade status under the British rule.

By far the most common type of painting support encountered in Liu Kang's works from the period under review was canvas and ground of type 2 . This observation allows us to conclude that the artist bought this type of 

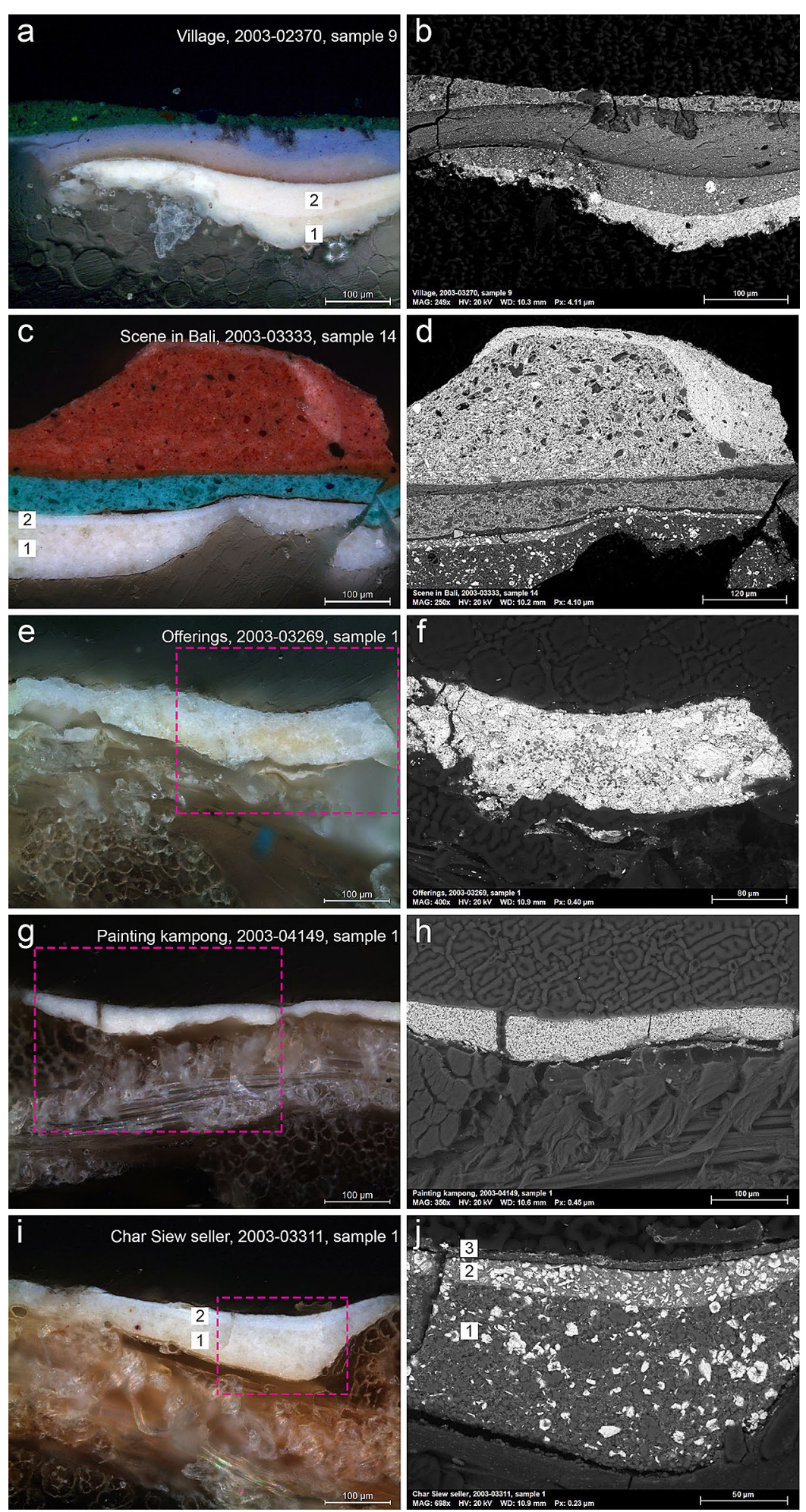

Fig. 4 Optical microscopy and corresponding backscattered electron (BSE) images of cross-sections representing five different types of the ground layer: $\mathbf{a}, \mathbf{b}$ double-layered ground of type 1 with a characteristic high concentration of lead white in the bottom layer and titanium white in the upper layer; $\mathbf{c}$, $\mathbf{d}$ double-layered ground of type 2 with a high concentration of chalk and clusters of lead white in the bottom layer and predominant lead white in the upper layer; $\mathbf{e}, \mathbf{f}$ single-layered ground of type 3 composed of zinc white; $\mathbf{g}, \mathbf{h}$ homogenous single-layered ground of type 4 formed from lead white and chalk; $\mathbf{i}$, j triple-layered ground of type 5 with the bottom layer mainly composed of chalk and lead white agglomerated in large aggregates, middle layer characterised by a high concentration of lead white, and top layer containing mainly titanium white 


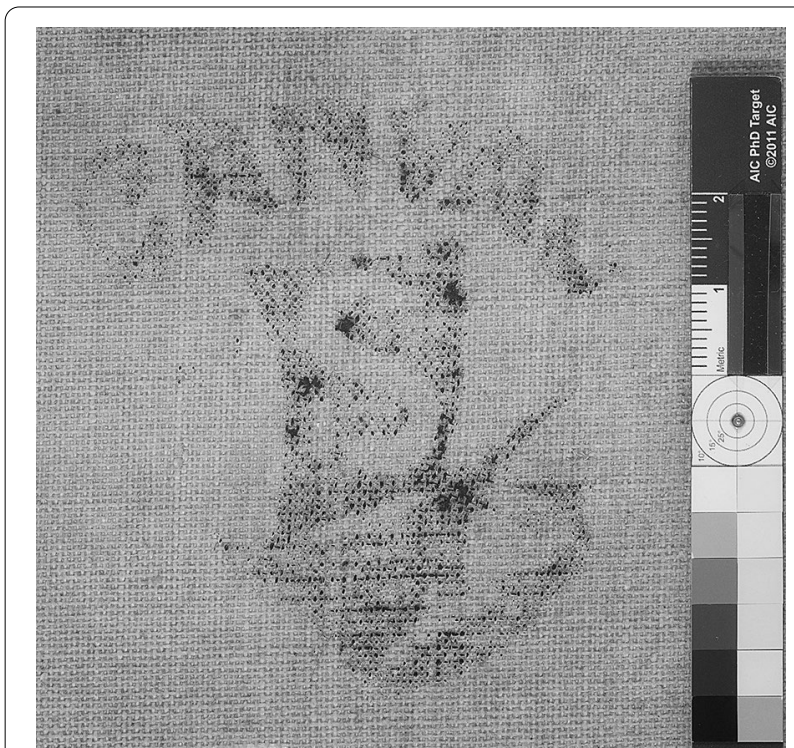

Fig. 5 Detail of the colourmen stamp on the reverse side of Village (1950), photographed in IR to enhance the legibility of the print

commercially prepared painting support in lengths and later cut it to the required size. The absence of a manufacturer's or retailer's stamp on the investigated paintings could support this notion [38]. Selling a canvas in lengths was a common industry practice; for instance, primed canvases from W\&N, R\&S and Rowney were offered by the yard or roll, typically 27 inches to 84 inches wide and 6 yards long.

The grounds of type 3 were applied over dense canvases of type 3. Likewise, the ground of type 4 was identified on a loose canvas of type 4. Exceptionally, the analyses showed that the ground of type 5 was applied over the canvas type 2 .

The imaging techniques as well as microscopic and spectral analyses revealed that four of the examined paintings were created over earlier rejected artworks and without the application of an intermediate ground layer. These observations support the notion that Liu Kang heavily relied on commercially prepared canvases and did not usually do self-preparation of the painting supports. The results obtained from the investigation of the painting supports are listed in Table 2: Appendix 1.

\section{Sketches, photographs and underdrawings}

Sketches form an important part of Liu Kang's painting practice as they demonstrate the process of the images' evolution, from studies to completed works. Most of the sketches discussed in this paper were executed by means of a pen, with crayon used sporadically. Confidently laid lines depict the forms and build the compositions with

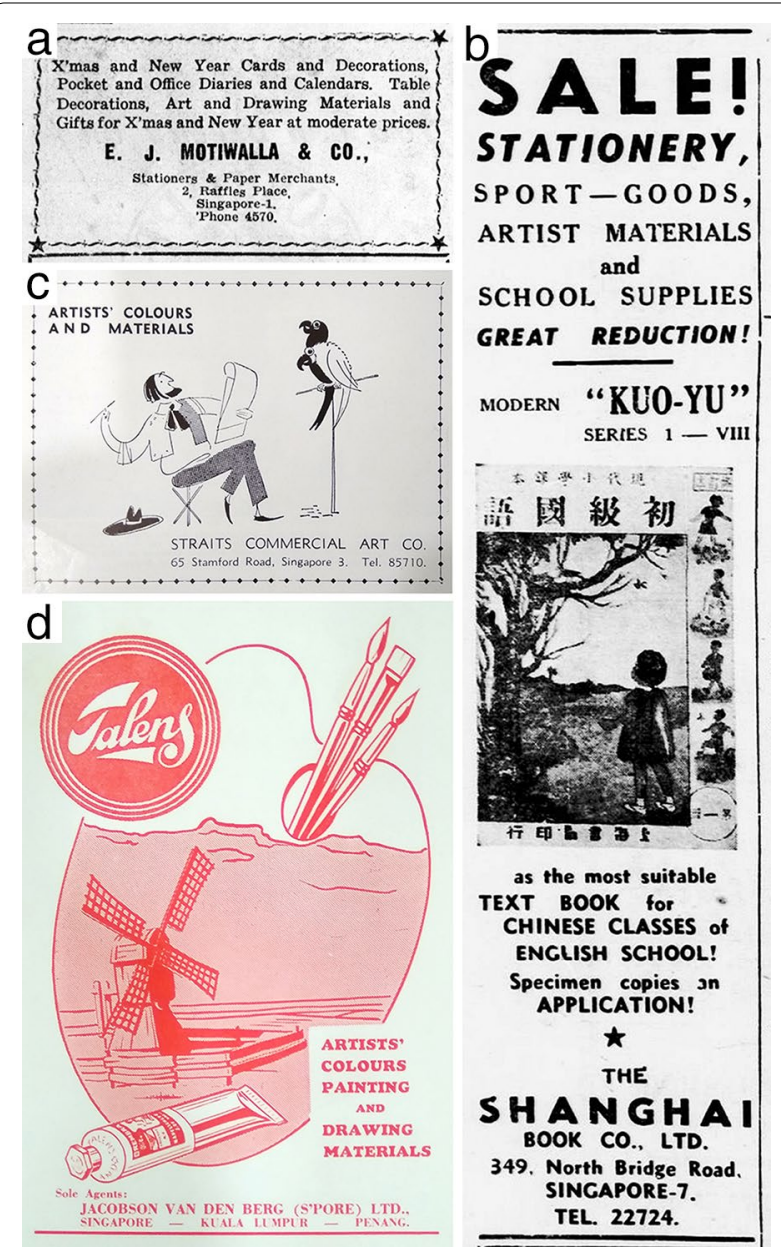

Fig. 6 Advertisements by retailers of art materials available in Singapore in 1950, 1951 and 1955: a E. J. Motiwalla \& Co.; b The Shanghai Book Co., Ltd.; c The Straits Commercial Art Co.; d Jacobson van den Berg (S'pore) Ltd

minimal grading, suggesting a rapid capturing of the scenes or subjects.

A comparison of the dates of the sketches and corresponding paintings indicates that some of Liu Kang's artistic ideas were taken up few years after initial conceptualisation on paper. For instance, Orchids was sketched in 1945, but the painted version was created in 1952 (Fig. 7a, b). A sketch of Boats bears the date 1950, whereas the painting was executed in 1956 (Fig. 7c, d). This observation strongly supports the hypothesis that sketching served as a convenient way of capturing interesting subjects that could be recalled for future use as reference material or as a starting point for a more ambitious painting project.

Some sketches reveal a process of searching for the best composition or form of expression. The painting Bali scene is accompanied by three sketches, which depict a gradual development of the idea for the painting. 

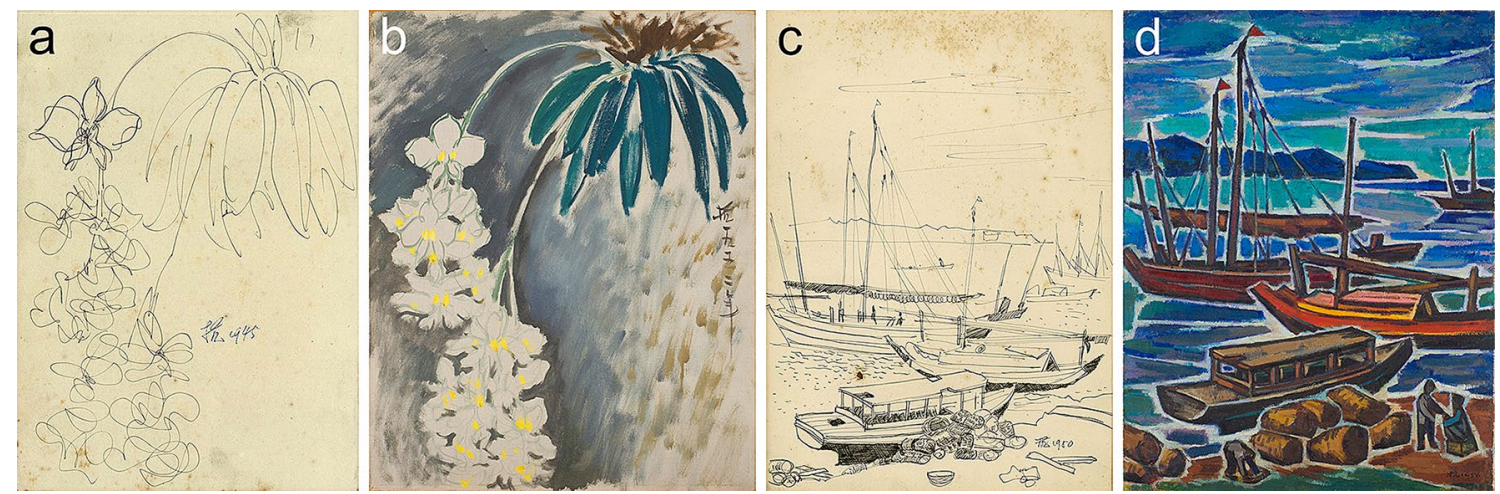

Fig. 7 a Liu Kang, Orchids, 1945, pen on paper, $25 \times 17.5$ cm. b Liu Kang, Orchids, 1952, oil on canvas, $50 \times 40.5$ cm. c Liu Kang, Boats, 1950, pen on paper, $34 \times 25.5 \mathrm{~cm}$. d Liu Kang, Boats, 1956, oil on canvas, $108.5 \times 88.5 \mathrm{~cm}$. Images a, c are from Liu Kang Family Collection. Images courtesy of Liu family

The first sketch (Fig. 8a) consists of several lines, which progressively evolve into a more detailed composition (Fig. 8b) finalised in the study of certain parts of the scenery (Fig. 8c). Hence, the painting appears to be a summary of the ideas studied in the three sketches (Fig. 8d).

The primary idea of the Char Siew seller, imaged in the classical pen sketch, explores a composition and studies a detail of a hand holding a chopper (Fig. 8e), whereas its crayon version reveals the artist's attempt at cubist expression (Fig. 8f), which evolved into the painting with evidently simplified and geometric forms (Fig. 8g). Likewise, the sketch Boats is striking in its precision, but there were far fewer details in the painted version of the scene, which also may resemble a cubist expression (Fig. 7c, d).

The sketch Painting kampong shows that the artist had initially considered a horizontal composition, but the painting evolved into a more detailed artwork, which was painted in the vertical orientation (Fig. 9a, b). By contrast, the simplicity of sketches for Orchids (Fig. 7a, b) and Kampong scene (Fig. 9c, d) was reflected in their painted versions, suggesting that the artist could have been satisfied with the initially imaged subject matter and composition and thus made no further changes.

In addition to sketching, Liu Kang frequently used pastels and a camera to document the subjects and motifs that inspired him. His pastel drawing and photograph capturing a procession of Balinese women with ritual offerings could have been used as a reference for depicting the details of the scene in Offerings upon his return to Singapore (Fig. 10). This suggests that he viewed the camera primarily as a tool to replicate the surrounding world in a precise manner [39].

Liu Kang's preparatory underdrawing stage was undoubtedly part of his working method. However, its evidence was recorded with VIS and IR only in Kampong scene and Painting kampong. As both artworks utilised the white colour of the exposed ground, the artist ensured that the underdrawings did not disturb an intended aesthetic effect. Thus, subtle pencil lines were drawn in Kampong scene (Fig. 11a, b), whereas in Painting kampong, the main shapes were lightly scratched into the white ground layer such that the grey colour of the canvas became visible (Fig. 11c). In Orchids, the composition was laid out directly with vigorous and effortless brushwork and diluted green paint, the latter seen especially in the decorative representation of the flower petals (Fig. 1c). A similar approach was evident in Village, Government office in Johore Bahru and Outdoor painting (Figs. 1a, d, 2a). The compositions of these three paintings were established with the painterly contour of light brown and violet paint and later reinforced with a calligraphic type of brushwork.

\section{Pigments}

Currently, there is, unfortunately, no information about the brands of the painting materials that Liu Kang used during the period under review. However, in his 1955 essay, the prominent Singapore artist and former President of the Singapore Art Society Ho Kok Hoe listed some pigments used by the artist at that time: "Viridian has become his favourite colour, with vermilion and Prussian blue to harmonize with it" [40]. The mentioned pigments are the primary colours of light-red, green and blue-and the most dominant colours in Liu Kang's paintings. Although viridian and Prussian blue were consistently used in the artist's earlier practice, vermilion is a new addition to the pictorial palette $[15,36,41,42]$. Thus, this information needed to be validated through the analytical methods. 

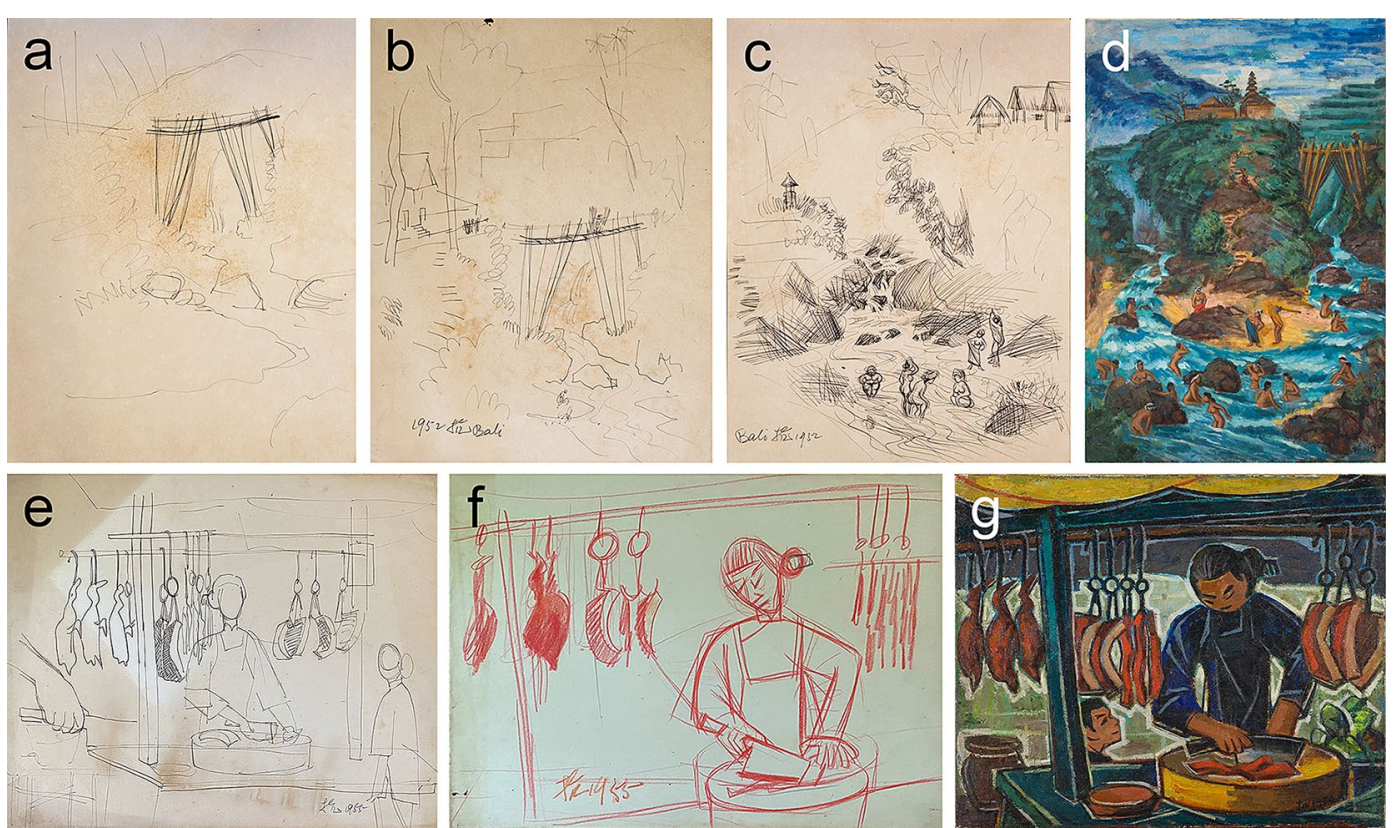

Fig. 8 a Liu Kang, Scene in Bali, undated, pen on paper, $32 \times 24.5$ cm. b, c Liu Kang, Scene in Bali, 1952, pen on paper, $32 \times 24.5$ cm. d Liu Kang, Scene in Bali, 1953, oil on canvas, $127 \times 85.5 \mathrm{~cm}$. e Liu Kang, Char Siew seller, 1955, pen on paper, $26.5 \times 34.5 \mathrm{~cm}$. f Liu Kang, Char Siew seller, 1955, crayon on paper, $27 \times 37.5 \mathrm{~cm}$. g Liu Kang, Char Siew seller, 1958, oil on canvas, $59.5 \times 72.5 \mathrm{~cm}$. Images a-c, e, f are from Liu Kang Family Collection. Images courtesy of Liu family

For clarity of the discussion, we decided to exclude the detailed characterisation protocols leading to the identification of the pigments commonly used by the artist based on the study of his earlier painting practice. The pigments frequently used by Liu Kang and characterised by the authors as employing the same methodology as in the current study are as follows: Prussian blue, ultramarine, cobalt blue, viridian, chrome yellow, yellow and red iron oxides, umber, organic reds, lithopone, barium white, zinc white, lead white, titanium white, chalk and carbon blacks $[15,36,41,42]$. Therefore, in this paper, the methodology and interpretation of the outcomes are focused on new pigments as well as other pigments used less frequently by the artist.

\section{Blue}

The analytical results of the blue painted areas showed that ultramarine (PB29) was the preferred blue pigment. It appears as a primary blue and is frequently used in combination with Prussian blue (PB27) and occasionally with viridian (PG18) to achieve different hues. The admixture of manganese blue (PB33) in Scene in Bali (sample 12) is a significant peculiarity, indicated first with SEM-EDS by the concomitant presence of Mn, Ba and S elements. FTIR completed this outcome by the detection of less intensive absorption peaks at 1417, 1403, 1364, $874,794,774$ and $752 \mathrm{~cm}^{-1}$, and strong absorption peaks at $1065\left(\left(\mathrm{SO}_{4}\right)^{2-}\right.$ stretching band), 631 and $600 \mathrm{~cm}^{-1}$ (both $\left(\mathrm{SO}_{4}\right)^{2-}$ bending band), which may be attributed to both manganese blue and lithopone (Fig. 12a-c).

Interestingly, the analyses of dark and light blue paints from the sky of Government office in Johore Bahru (samples 22 and 3) revealed complex mixtures of pigments. Although both paints appeared red in the IRFC, this outcome suggested the use of ultramarine and/or Co-, and $\mathrm{Cr}$-containing pigments. It also suggested the absence of Prussian blue, which usually contributes to the blue hue of IRFC images. The PLM observation of the blue particles in sample 22, extracted from the upper, darker part of the sky, was inconclusive. It only allowed us to distinguish between ultramarine (isotropic particles with low refractive index turn red with Chelsea filter) and other isotropic blue particles that also appear red with Chelsea filter but which have high refractive indexes. Thus, cobalt blue and cerulean blue were considered as they share similar optical features. The co-location of Co and Sn elements recorded with SEM-EDS suggested the presence of cerulean blue (PB35). As for cobalt blue, the elemental analysis provided an ambiguous result because the Alsignal recorded in the sample may be attributed to both ultramarine and cobalt blue (PB29). The coincident PLM and SEM-EDS analyses also suggested a trace admixture of viridian in the blue paint. FTIR confirmation of viridian, cerulean and cobalt blues was hindered due to 

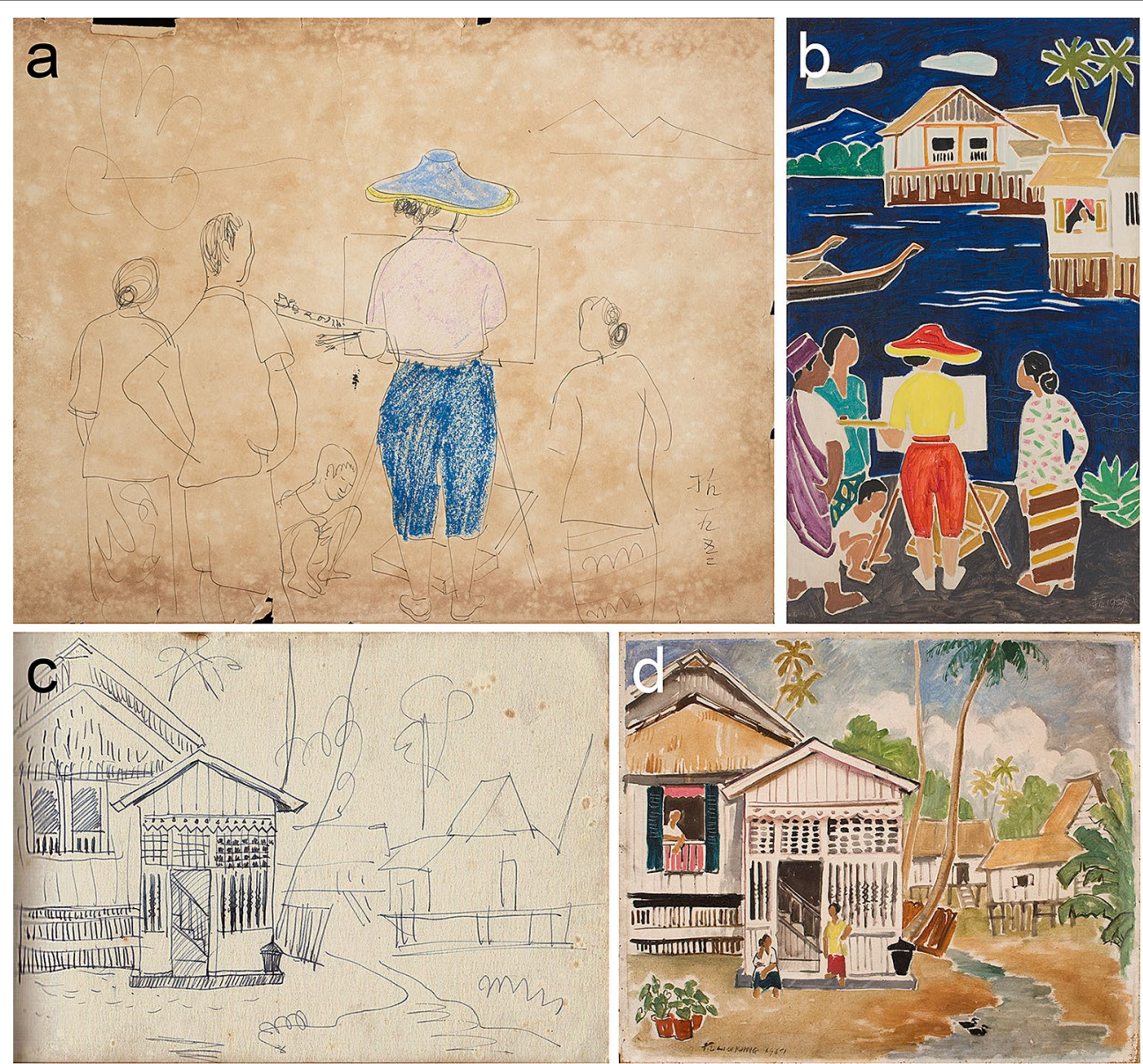

Fig. 9 a Liu Kang, Painting kampong, 1952, pen and crayon on paper, $30 \times 38 \mathrm{~cm}$. Liu Kang Family Collection. Image courtesy of Liu family. b Liu Kang, Painting kampong, 1954, oil on canvas, $120.5 \times 71 \mathrm{~cm}$. c Liu Kang, Kampong scene, undated, pen on paper, $14 \times 19 \mathrm{~cm}$. Gift of the artist's family. Collection of National Gallery Singapore. $\mathbf{d}$ Liu Kang, Kampong scene, 1951, oil on canvas, $60 \times 72.5 \mathrm{~cm}$
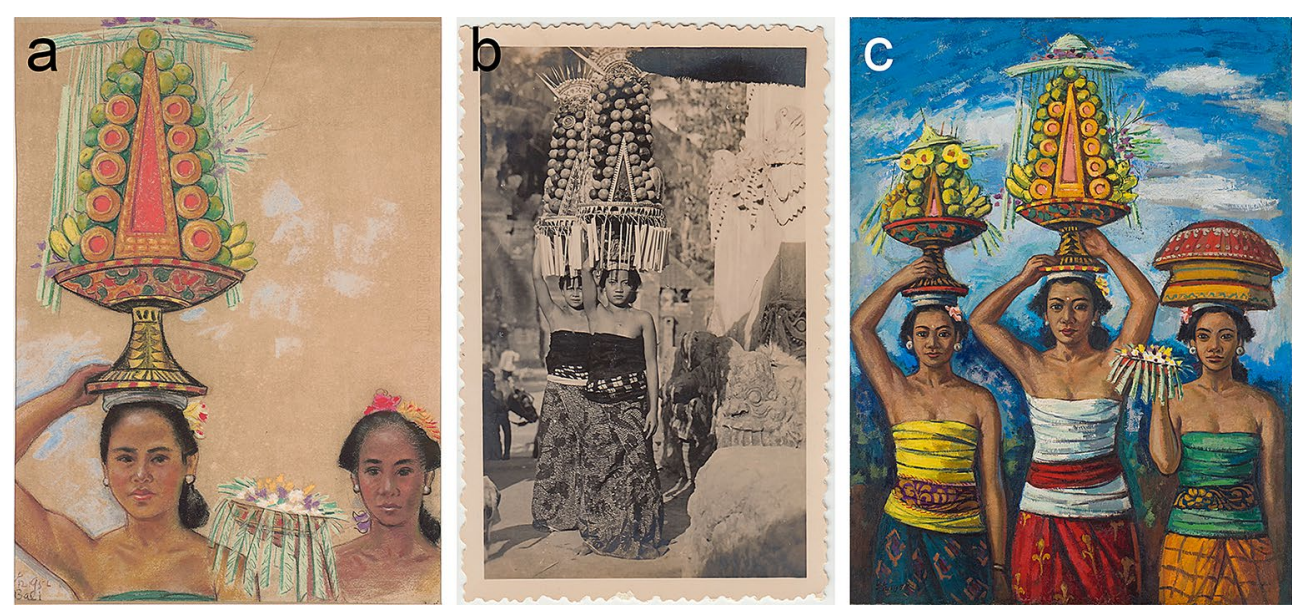

Fig. 10 a Liu Kang, Balinese woman carrying offering, 1952, pastel on paper, $63 \times 46 \mathrm{~cm}$. Gift of the artist's family. Collection of National Gallery Singapore. b Archival photograph from Bali by Liu Kang, undated. Liu Kang Family Collection. Image courtesy of Liu family. c Liu Kang, Offerings, 1953 , oil on canvas, $131.5 \times 98.5 \mathrm{~cm}$ 

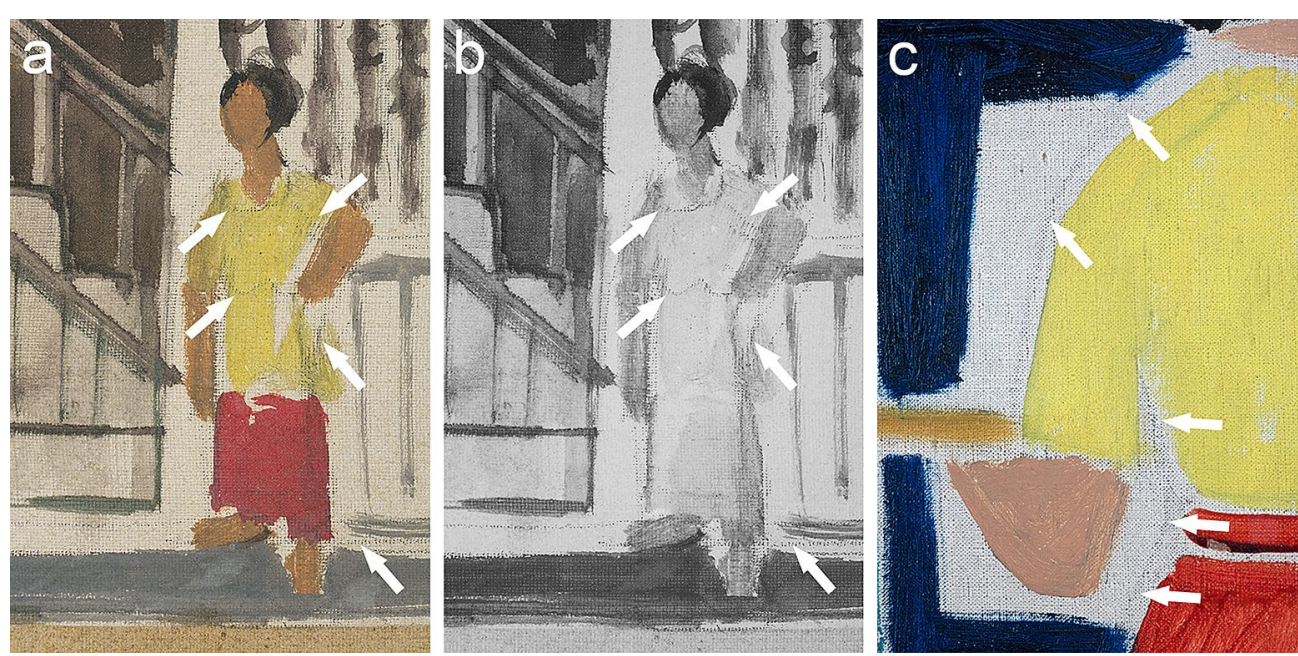

Fig. 11 VIS and corresponding IR detail images of Kampong scene $(\mathbf{a}, \mathbf{b})$, and VIS detail image of Painting kampong (c). The arrows indicate the presence of the preparatory underdrawing $(\mathbf{a}, \mathbf{b})$ and scratched contour into the white ground $(\mathbf{c})$

the strong IR absorption induced by other compounds overlapping with less intensive peaks of the pigments in question [43]. Moreover, their fundamental bands were outside of the spectral range of the instrument. The analyses of sample 3, extracted from the bottom, brighter part of the sky of Government office in Johore Bahru, were conducted only with PLM and SEM-EDS, which suggested the presence of cerulean blue and the absence of ultramarine and viridian. Thus, the admixture of cobalt blue can be considered based on the presence of $\mathrm{Al}$ in the examined paint mixture.

The use of phthalocyanine blue (PB15) was suggested by the consistent $\mathrm{XRF}$ recording of $\mathrm{Cu}$-signal in the areas of water, mountain and sky of Painting kampong (spots $122,123,125)$. It was additionally confirmed with the SEM-EDS detection of $\mathrm{Cu}$ in sample 3. The FTIR spectra corroborated this result with a complex array of the absorption peaks at 1508 attributed to $\mathrm{C}=\mathrm{N}$ stretching in the aromatic rings, 1334, 1166, 1088 and 729 corresponding to the phthalocyanine skeleton vibrations and other typical absorption bands at 1462, 1420, 1378, 1287, 1264, $1005,957,900,801,780 \mathrm{~cm}^{-1}$. The low frequency peak at $754 \mathrm{~cm}^{-1}$ corresponds to the phthalocyanine ring vibrations (Fig. 12d-f) [44, 45]. The execution of the painting indicates a thorough planning process that probably included the choice of pigments. Thus, the use of phthalocyanine blue is not an accidental but a deliberate decision to replace ultramarine and/or Prussian blue with a new pigment of similar optical quality. However, it is puzzling why the artist did not incorporate this new blue pigment in his further practice in the 1950s. The reason could be the lack of availability of the pigment or a conscious decision to reject it.
The contemporary colourmen catalogues confirmed that phthalocyanine blue was available from W\&N as Winsor blue (Fig. 13), from Rowney as Monastral blue, and from R\&S as Reeves blue. Manganese blue was listed by W\&N in two hues, as manganese blue and mineral blue (Fig. 13). Based on the analyses, Liu Kang did not seem to have been particularly attracted to Prussian blue, contrary to the observation made by Ho Kok Hoe. This blue pigment appears only in mixtures while ultramarine seems to be a preferred blue, although some experimentation with cerulean, cobalt, manganese and phthalocyanine blues was confirmed.

\section{Green}

Greens, more than any other colour, symbolise the lush tropical vegetation that impressed Liu Kang. Hence, he preferred viridian, probably for its intense brilliance; however, viridian was frequently blended with ultramarine and Prussian blue to modify the hue. As cerulean blue and cobalt blue were probably used for depicting the sky in Government office in Johore Bahru, their presence in the green passages of the same painting is understandable (sample 6). However, PLM and SEM-EDS provided some indications of cerulean blue, while the presence of cobalt blue remains uncertain.

Besides viridian, another green pigment, emerald green (PG21), was identified in Orchids (sample 5) by the SEMEDS detection of $\mathrm{Cu}$ - and As-signals and FTIR spectra depicting less intensive ester group stretching absorption peak at $1552 \mathrm{~cm}^{-1}$, peaks at 1451 and $754 \mathrm{~cm}^{-1}$ (both masked by the intensive peaks of the acrylic resin used for the embedding sample 5) and an absorption peak of $632 \mathrm{~cm}^{-1}$ overlapped by the signal from 

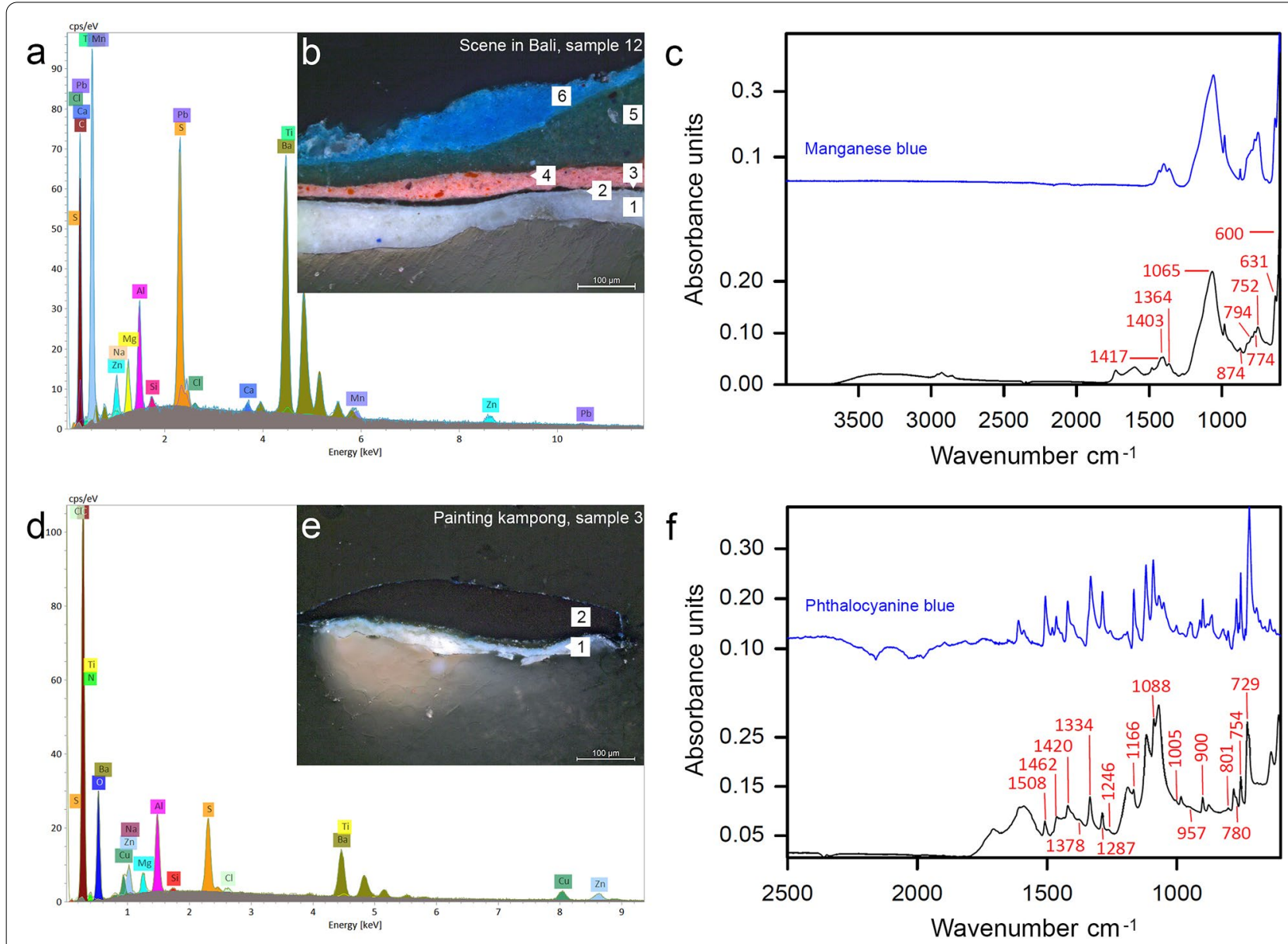

Fig. 12 a SEM-EDS spectra of the blue paint from layer 6 of sample 12 extracted from Scene in Bali; $\mathbf{b}$ optical microscopy image of the cross-section of the sample; c corresponding ATR-FTIR spectra of the layer 6 with labelled marker peaks of manganese blue and reference spectra of the same pigment; $\mathbf{d}$ SEM-EDS spectra of dark, blue paint from layer 2 of sample 3 extracted from Painting kampong; e optical microscopy image of the cross-section of the sample; $\mathbf{f}$ corresponding ATR-FTIR spectra of the layer 2 with labelled marker peaks of phthalocyanine blue and reference spectra of the same pigment

lithopone [46]. Emerald green is considered in sample 9 from Village, based on the concomitant presence of $\mathrm{Cu}$ and As elements; however, their minimal concentration may indicate that this pigment was used as an admixture. The trace presence of elemental copper alone in the same painting (sample 18) suggests paint contamination from emerald green. This result resembles Liu Kang's barely discernible use of emerald green in France (1929-1932), during which time he was also not convinced about giving the hue a more pronounced role in the painting process $[15,42]$. The SEM-EDS recording of $\mathrm{Cu}$ accompanied by strong $\mathrm{Cl}$-signal, as well as FTIR detection of the strong absorption bands occurring at 1496, 1391, 1321, 1305, 1277, 1208, 1152, 948, 770 and $748 \mathrm{~cm}^{-1}$, matching with the IRUG reference [47], enabled the phthalocyanine green (PG7) to be identified in the green paint mixture from Char Siew seller (sample 4) (Fig. 14a-c) [48]. This green pigment was also detected in Outdoor painting (sample 5) based on the trace $\mathrm{Cu}$-signal and absorption peaks at 1390, 1305, 1273, 1095, 951 and $767 \mathrm{~cm}^{-1}$. According to W\&N (Fig. 13), Rowney and R\&S catalogues of oil paints, emerald green was still available despite its high toxicity. Phthalocyanine green was sold as Winsor green by W\&N (Fig. 13), as Monastral green by Rowney and as Reeves green by R\&S.

Brighter and warmer green hues were achieved by adding cadmium yellow (PY35) or its variant-light cadmium yellow (co-precipitated cadmium sulfide and zinc sulfide) or cadmium yellow lithopone (co-precipitated cadmium zinc sulfide and barium sulfate) [49]- which was detected in more than half of the investigated green paint mixtures. The detection of a concomitant presence of $\mathrm{Cd}$, 


\title{
Composition of Pigments
}

\author{
PREPARED BY
}

\section{WINSOR \& NEWTON LTD}

and used by them in the manufacture of their Artists' Oil and Water Colours.

Cadmium Lemon .

Cadmium Yellow Pale

Cadmium Yellow ...

Cadmium Yellow Deep

Cadmium Green

Cadmium Green Pale

Cadmium Orange ..

Cadmium Red

Cadmium Red Deep

Cadmium Scarlet
Different shades of Sulphide of Cadmium.

Mixtures of Cadmium Yellow and Viridian.

Combinations of Sulphide of Cadmium with Selenide of Cadmium.
Emerald Green

Emerald Oxide

of Chromium

Emeraude Green

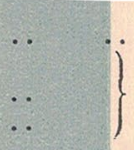

Aceto-Arsenite of Copper.

Synonymous with Viridian.
Geranium Lake

Manganese Blue
A fugitive Lake prepared from a soluble Coal Tar dye.

Mineral Blue $\quad \ldots \quad$.. Synonymous with Manganese Blue

Permanent Green Light

Permanent Green ..

Permanent Green Deep

Winsor Blue

.. Copper Phthalocyanine. An organic pigment of exceptional brilliance and durability. The original dyestuff was introduced by I.C.I. in 1935 under the name of Monastral Fast Blue.

Winsor Green $\quad . \quad$.. Chlorinated Copper Phthalocyanine. A green pigment corresponding to Winsor Blue in exceptional brilliance and durability, derived from the dyestuff originally introduced by I.C.I. as Monastral Fast Green.

\section{Zinc Yellow $\quad$. $\quad$.. Chromate of Zinc.}

Fig. 13 Selected compositions of pigments, listed in the catalogue of W\&N from 1957, used for the manufacturing of oil and watercolours 

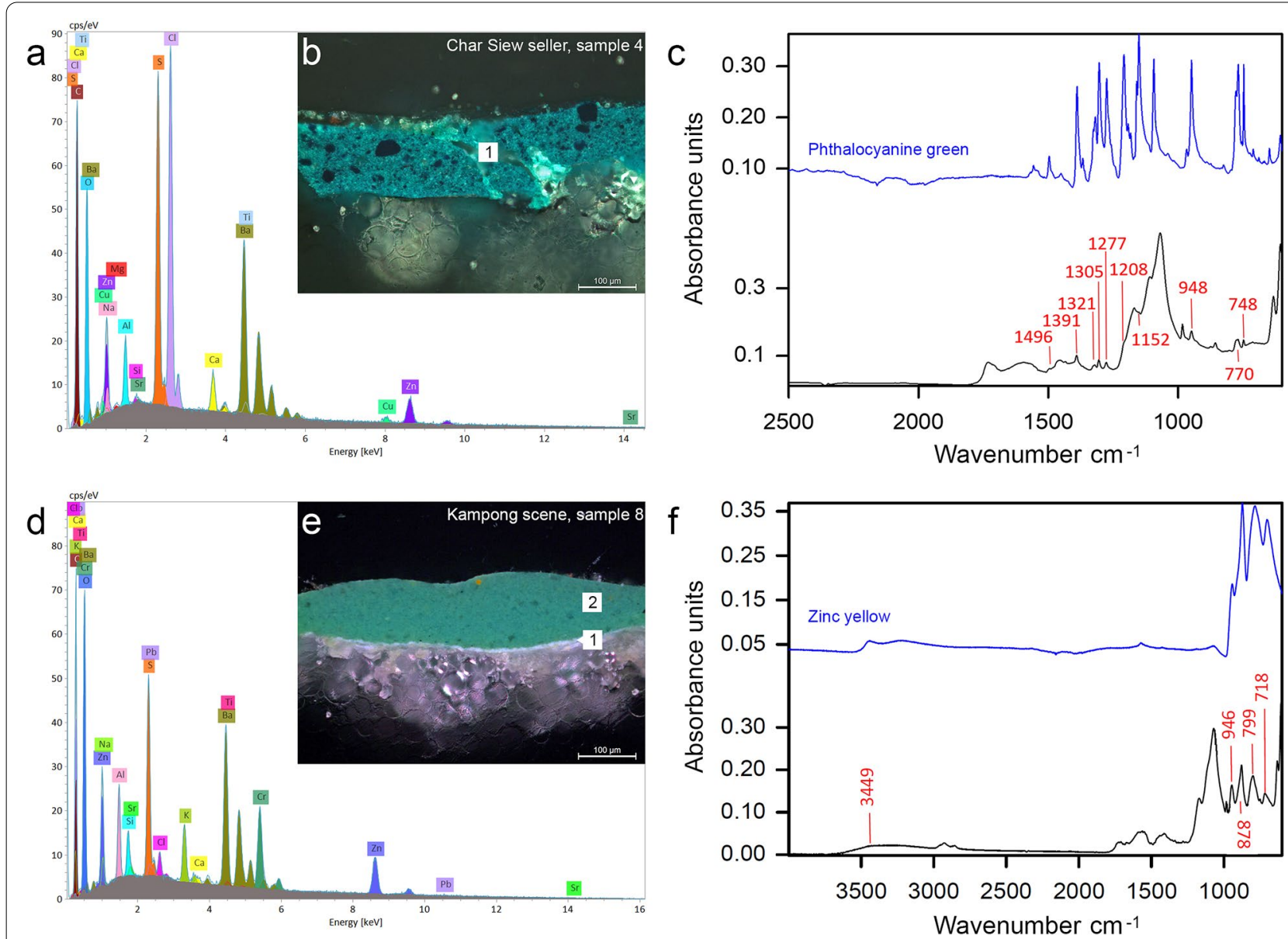

Fig. 14 a SEM-EDS spectra of the green paint of sample 4 extracted from Char Siew seller; $\mathbf{b}$ optical microscopy image of the cross-section of the sample; c corresponding ATR-FTIR spectra of the green paint with labelled marker peaks of phthalocyanine green and reference spectra of the same pigment; $\mathbf{d}$ SEM-EDS spectra of the green paint from layer 2 of sample 8 extracted from Kampong scene; e optical microscopy image of the cross-section of the sample; $\mathbf{f}$ corresponding ATR-FTIR spectra of the green paint with labelled marker peaks of zinc yellow and reference spectra of the same pigment

$\mathrm{S}$, Se and Ba in sample 9 from Village seems to point to cadmium orange (PO20) and barium white or cadmium orange lithopone (co-precipitated cadmium sulfide selenide and barium sulfate). However, a precise characterisation of cadmium-based pigments was difficult due to their incorporation with other pigments. A concomitant presence of cadmium yellow and viridian can also be related to the commercial mixture of these two pigments, known as cadmium green (PG14) [50]. Such composite paint was available in two hues from W\&N (Fig. 13) and in one hue from Rowney.

Chrome yellow (PY34), which is known from Liu Kang's earlier practice, was found as a frequent admixture to green paints. However, a concomitant presence of chrome yellow and Prussian blue may suggest commercially and commonly available chrome green (PG15).

In addition, the green paints, obtained by combining either Prussian blue or ultramarine, or both, and
$\mathrm{Cd}$ - and/or Cr-containing yellow(s), were found in four of the investigated paintings. Interestingly, FTIR signatures for zinc yellow (PY36) admixture were confirmed in five investigated green paints. This admixture was clearly evident in the spectra recorded from the green paint of Kampong scene (sample 8) by characteristic peaks at $3449,946,878,799$ and $718 \mathrm{~cm}^{-1}$ (Fig. 14d-f) [51]. The detection of this pigment is particularly rewarding as, according to the literature, it was unpopular among artists [52]. Rowney and R\&S did not list the pigment, although it was available from W\&N (Fig. 13). Moreover, W\&N advertised a commercial mixture of viridian and zinc yellow under the name of permanent green, and it was available in three hues (Fig. 13).

The analyses reflect Liu Kang' predilection for viridian, which conforms with Ho Kok Hoe's statement. Moreover, they point towards the conclusion that 
viridian and its intensive combinations with ultramarine, Prussian blue and cadmium yellow were used to obtain various hues of green colour.

\section{Yellow}

The analyses suggest that most of the investigated yellow paint mixtures are composed of cadmium yellow or its variant. Cadmopone is very likely in the yellow paint from Kampong scene, based on the concomitant presence of $\mathrm{Cd}, \mathrm{Ba}$ and $\mathrm{S}$ recorded with XRF (spot 2060). The trace presence of Se, identified only in sample 8 from Offerings, suggests either cadmium orange or cadmium orange lithopone due to the Ba-signal recorded with SEM-EDS [49]. Chrome yellow and zinc yellow very seldom appear in the yellow paints; however, the artist used these yellow pigments more frequently as admixtures to green paints. Overall, there is a noticeably reduced role of chrome yellow in favour of cadmium yellow when compared to Liu Kang's paintings from the Paris period (1929-1932) [15], where chrome yellow was a prevailing yellow pigment. Yellow iron oxide (PY43) appears intermittently and usually in combination with other yellows. Its pronounced presence was detected only in sample 12 of Government office in Johore Bahru. The concomitant presence of $\mathrm{K}$ and Co elements in the yellow paint samples from Bali scene (sample 9) and Char Siew seller (sample 6) pointed to the use of cobalt yellow (PY40). The SEMEDS elemental analysis of the latter sample was additionally validated with FTIR by peaks at 2709, 2651, $1387,1328,1179,828$ and $632 \mathrm{~cm}^{-1}$, matching with the IRUG reference [53] (Fig. 15a-c).

\section{Brown}

Brown colours primarily consist of yellow and red iron oxides, sometimes modified with $\mathrm{Cr}$ - and/or Cd-containing yellow(s). Darker shades were obtained by adding bone black (PBk9) or umber (PBr7). Judging from the XRF analysis of a dark-brown passage in Painting kampong (spot 54), the paint probably involves umber and eosin-derived geranium lake (PR90:1). The latter is assumed based on the $\mathrm{Br} \mathrm{K \alpha} \alpha_{1}$ signal at $11.92 \mathrm{keV}$ and $\mathrm{Br}$ $\mathrm{K} \beta_{1}$ signal at $13.29 \mathrm{keV}[54-56]$.

\section{Red}

The PLM of the red paints allowed us to observe a good deal of the red particles characterised by the unique low refractive index, indicative of the organic reds. Further FTIR characterisation of the organic reds was complicated due to the interference of the oil and compounds relating to other pigments present within the bulk of the investigated mixtures. For instance, yellow iron oxides, chrome and cadmium yellows were mixed with organic reds by the artists to produce different red hues. Cooler and/or deeper shades were achieved by adding bone black or ultramarine. Nevertheless, the Br-signal recorded with SEM-EDS in four investigated samples could be linked with the geranium lake. It features strongly in Boats (sample 7), where it was probably applied in a less modified form than in other paintings. Hence, the SEMEDS additionally allowed us to detect $\mathrm{Pb}-, \mathrm{Ba}-, \mathrm{Al}-$, and $\mathrm{S}$-signals, suggesting precipitation of eosin onto a $\mathrm{Pb}$ - or Al-based substrate [50, 54-60] and probable commercial admixture of barium white extender. A comparison of the FTIR spectra of sample 7 from Boats with the reference spectra of eosin $\mathrm{Y}$ allowed us to observe some evident
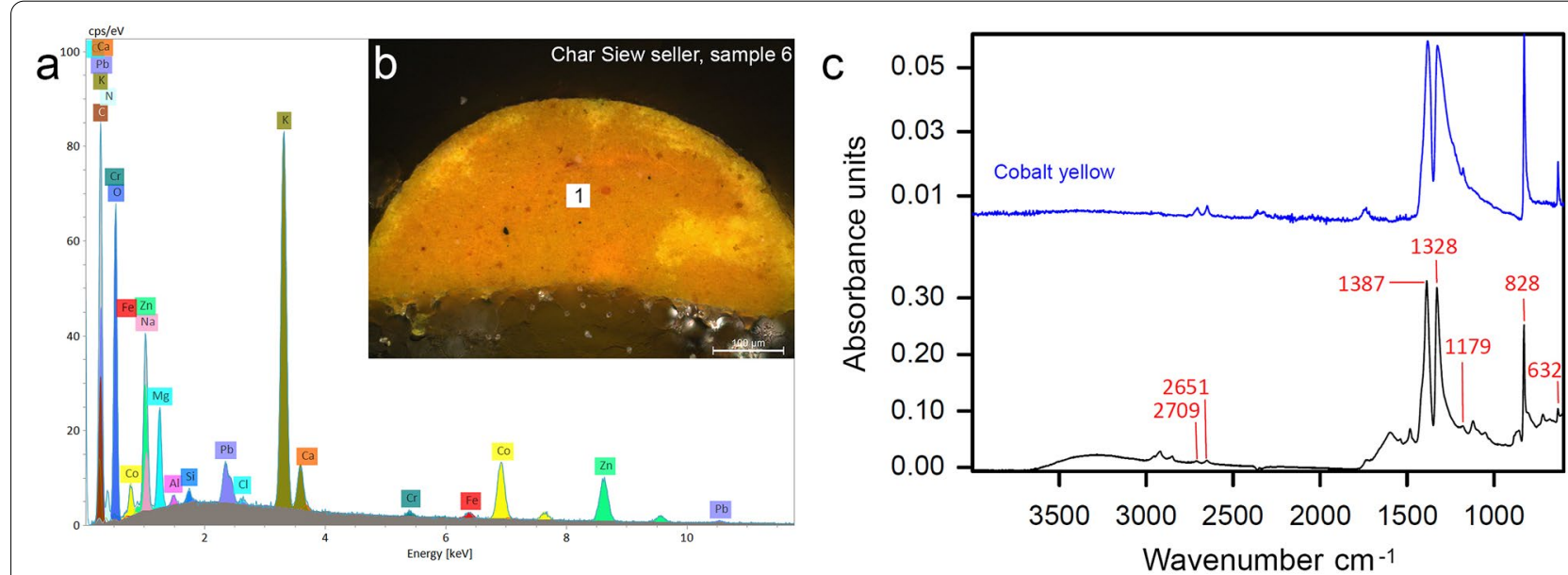

Fig. 15 a SEM-EDS spectra of the yellow paint of sample 6 extracted from Char Siew seller; $\mathbf{b}$ optical microscopy image of the cross-section of the sample; c corresponding ATR-FTIR spectra of the yellow paint with labelled marker peaks of cobalt yellow and reference spectra of the same pigment 
similarities of the IR absorption peaks at 3353, ca. 1549, 1459,1341 , ca. 1231 , ca. $975,882,761$, and ca. $715 \mathrm{~cm}^{-1}$ (Fig. 16a) [61, 62]. FTIR analyses of the remaining three samples did not produce sufficient results to univocally assign the Br-containing pigment to eosin.

The FTIR spectra of a red paint from Char Siew seller (sample 3) allowed us to reveal features consistent with red azo pigment naphthol red AS-D (PR112) by various absorption bands matching the reference sample at 3276, 3237, 3188, 3125, 3074, 3039, 3027, 1667, 1603, 1593, $1544,1492,1477,1447,1420,1404,1364,1323,1279$, $1257,1237,1154,1012,965,905,890,856$ and $814 \mathrm{~cm}^{-1}$, and the IRUG reference (Fig. 16b) [63, 64].

An anthraquinone derivative was characterised with FTIR in Kampong scene (sample 10) by absorption bands at 1631, 1590, 1529, 1463, 1383, 1358, 1267, 1187, 1025, 905, 839, 769, 720 and $669 \mathrm{~cm}^{-1}$ (Fig. 16c), indicating synthetic alizarin lake (PR83:1) [65], whereas a high concentration of $\mathrm{Al}$ in the sample could be related to an aluminium-containing substrate $[63,66]$. Similar FTIR spectra features were recorded in the red paint from Village (sample 25).

In Outdoor painting (sample 7), a strong Al-signal, recorded with SEM-EDS and FTIR absorption bands at 1636, 1577, 1527, 1463, 1363, 1287, 1097, 982 and $841 \mathrm{~cm}^{-1}$, might be indicative of an aluminium-based substrate for the organic red pigment.

The catalogue search revealed that the geranium lake from W\&N was derived from coal tar (Fig. 13), which is different from that identified in Liu Kang's paintings. Rowney listed geranium lake without a description of the chemical composition and R\&S did not sell it at all. It is interesting to note that an eosin-based red lake pigment was identified earlier in one of Liu Kang's paintings, which was created in France in 1931. However, its isolated appearance could be explained by the high price of the paint [15].
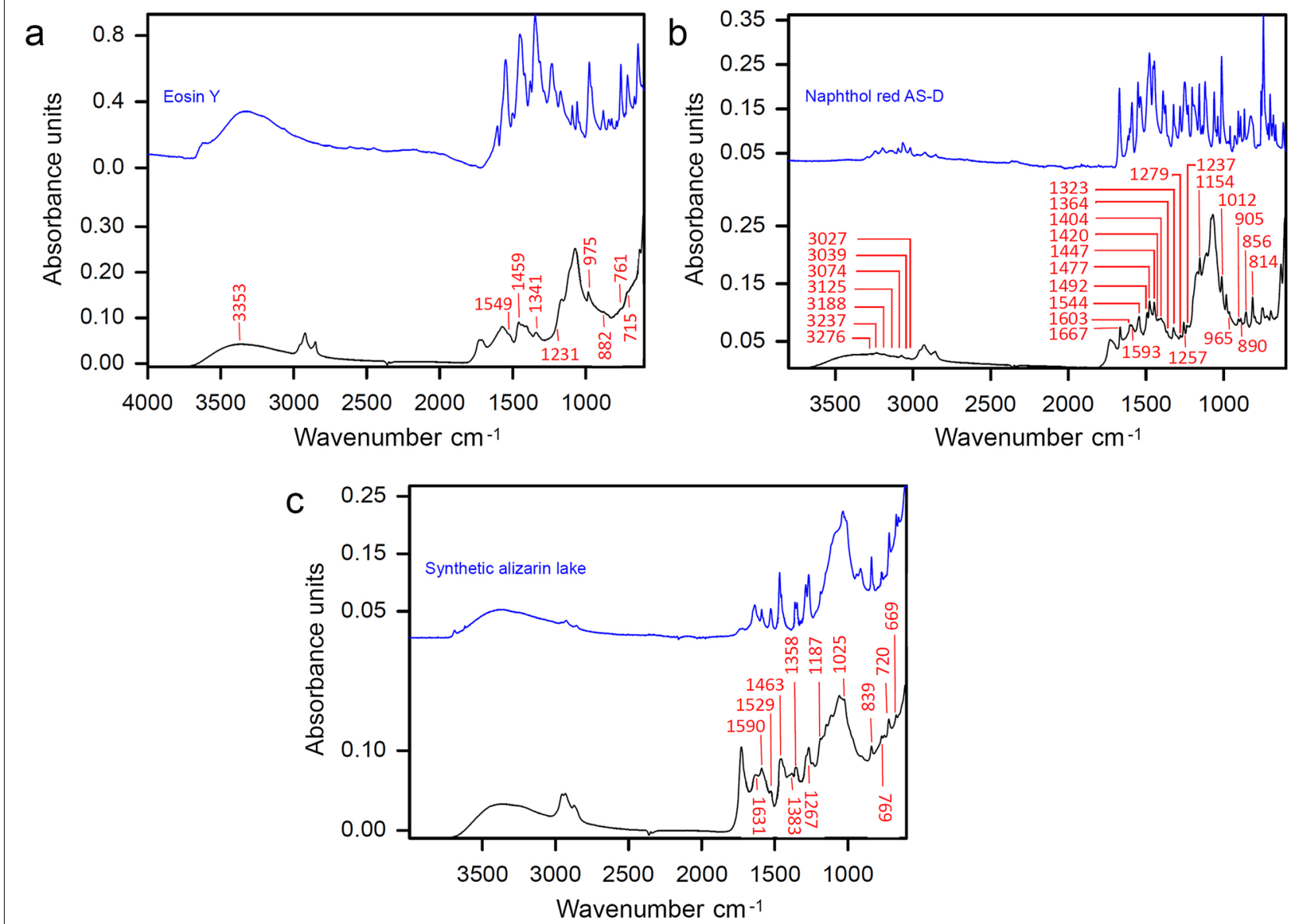

Fig. 16 a ATR-FTIR spectra of the red paint of sample 7 extracted from Boats with labelled marker peaks of organic red and reference spectra of eosin Y; $\mathbf{b}$ ATR-FTIR spectra of the red paint of sample 3 extracted from Char Siew seller with labelled marker peaks of organic red and reference spectra of naphthol red AS-D; c ATR-FTIR spectra of the red paint of sample 10 extracted from Kampong scene with labelled marker peaks of organic red and reference spectra of synthetic alizarin lake 
The analyses also support the use of cadmium red (PR108) or its variant cadmium red lithopone (co-precipitated cadmium sulfide selenide and barium sulfate), detected in four paint mixtures. Red iron oxide (PR101) appears only once in Village (sample 25). Interestingly, we did not detect vermilion (PR106) in the investigated red paint samples, although it was reported by Ho Kok Hoe as being Liu Kang's "important" red [40]. As the pigment was listed by W\&N, R\&S and Rowney, it can be hypothesised that it was available in Singapore. While the absence of vermilion in the analysed samples may seem surprising, the possible explanation could be that Ho Kok Hoe's account is inaccurate, or the artist used some substitute for vermilion sold under a similar name. For instance, composite paints like vermilionette or American vermilion involved eosin-based lake pigment or scarlet dye combined with red lead or chrome red [50, $67,68]$. Moreover, the recent study of the Royal Talens paints identified a composite of three synthetic organic pigments, PR51, PR3 and PR63, in a vermilion imitation tube [69]. Although it is challenging to identify the organic red pigments, the analytical data suggested their discernible presence in the studied samples, leading to the hypothesis that some of these pigments could form the commercial substitution of vermilion. However, more analyses involving chromatography and a range of mass and vibrational spectroscopy techniques are needed to better characterise the red paint mixtures [70,71].

\section{White}

The analyses of white paints did not reveal the preferential use of any white pigment. For instance, the UVR imaging of the Village suggests that the grey paint used for the clouds was achieved with different white pigments (Fig. 17a, b). The SEM-EDS analysis of the cloud imaged dark in UVR (sample 4) suggested a high concentration of zinc white with trace presence of chalk and lead white. Although sampling from the adjacent cloud was restricted, lead white and/or lithopone was probably involved in painting, based on their unique ability to reflect UV $[18,19]$. Based on the UVR imaging and SEM-EDS analyses, lead white was primarily used in the white passages of Scene in Bali. The analyses of white brushstrokes in Offerings, Boats and Char Siew seller suggested a greater use of lithopone and/or barium white and zinc white with minor admixtures of chalk, lead and titanium whites.

It is worth noting that in Kampong scene, Orchids, Government office in Johore Bahru, Outdoor painting and Painting kampong, Liu Kang intentionally exposed a white ground layer during the painting process instead of using white paint for highlights (Figs. 1b-d and 2a, b).
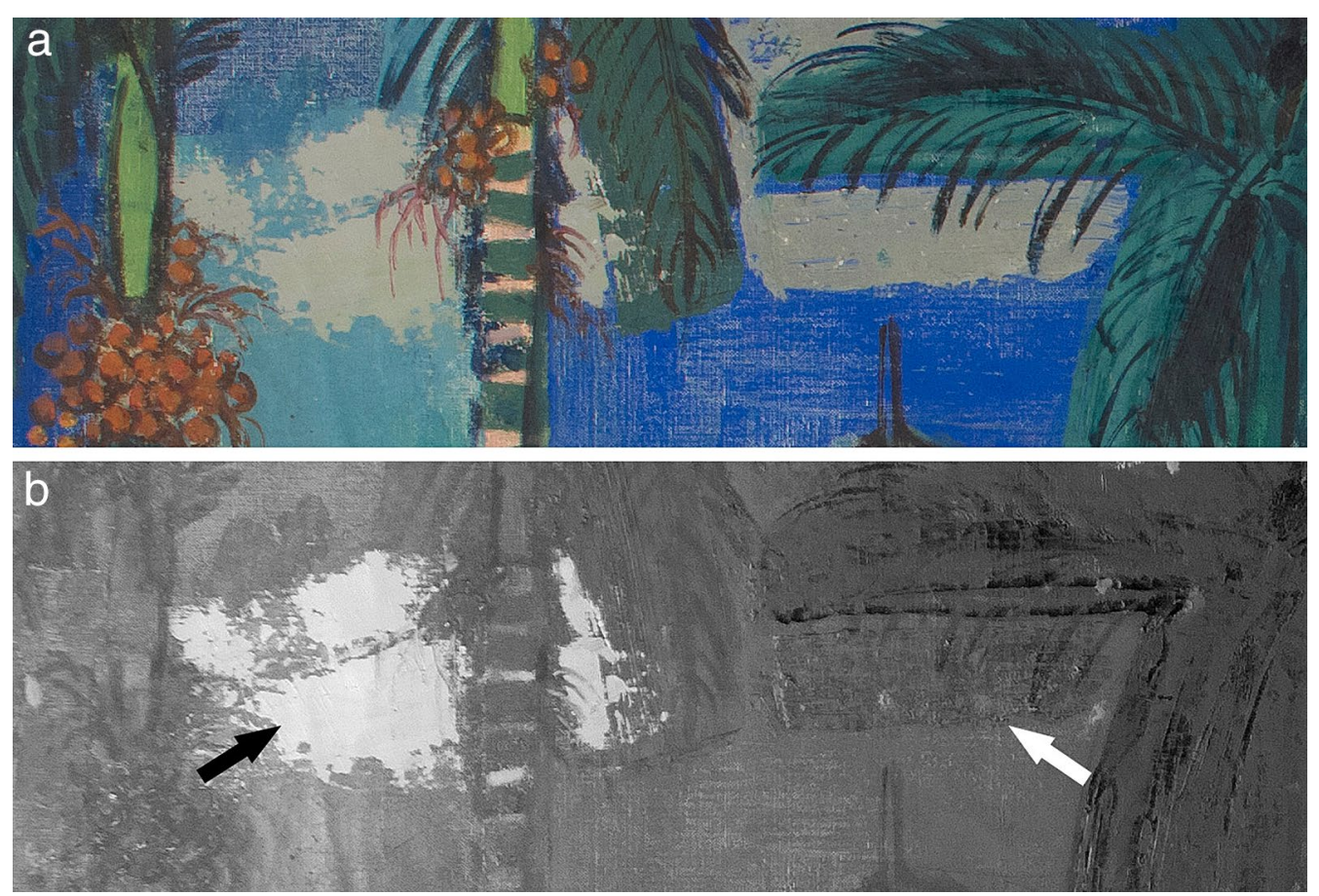

Fig. 17 VIS (a) and corresponding UVR detail image (b) of Village, indicating that white paint from the cloud on the left (black arrow) has a strong UV reflectance, suggesting a presence of lead white and/or lithopone, whereas the cloud on the right (white arrow) shows UV absorbance, suggesting application of zinc white, confirmed through SEM-EDS analysis 


\section{Black}

Black paint brushstrokes appear intermittently only in Kampong scene, Government office in Johore Bahru and Painting kampong. From the XRF point measurements and SEM-EDS analyses of samples, we deduce the preferential use of bone black. This pigment also appears in combination with other colours as a minor admixture.

\section{Binding media and other identified compounds}

The analyses of the binding media carried out using FTIR showed that an oil binder had been used in every painting. The analyses also revealed that, in a few paint samples, the oil was converted into metal soaps from the chemical reaction between the saturated fatty acids of the lipidic binder and the metal ions of the lead white and zinc white present in the paint layers. The results of the paint analyses are summarised in Table 3: Appendix 2.

\section{Painting technique}

The investigated paintings show an evolution of the artist's technique during the period under review. His artworks from 1950 to 1953 are executed with a broad and flat application of the local colours, a marginal suggestion of light effects and minimal introduction of details. Village and Government office in Johore Bahru attract attention through a strong colour block division resembling the influence of the Post-Impressionists, while the bold outlines hint at the influence of Chinese calligraphy. A confident establishment of the compositional and colouristic structures is distinct in Kampong scene, Orchids and Government office in Johore Bahru. In these paintings, the compositional outlines were skilfully filled in with washes of heavily diluted paint; however, the artist left certain parts of white ground exposed, producing attractive optical effects (Fig. 18a).

The painting technique in two other artworks from 1953, Scene in Bali and Offerings (Fig. 1e, f), significantly differs from the previous artworks. Probably due to his fascination with the subject matter, which is rich in details and decorative motifs, the artist has chosen a descriptive way of expression. The static, portrait-like composition of three women and their batik costumes and offering stands in Offerings reveals a temptation to realistically depict the female beauty in and richness of the indigenous Balinese culture. In contrast, the Bali scene is characterised by crowds of nude figures taking a bath in a river, which is flowing down the mountain, and surrounded by the picturesque landscape. The extent of the visual impact of that exotic place on Liu Kang can be elucidated from his essay, written in the year following his Bali sojourn. The essay creates an image of Bali as a place where idyllic landscapes, great architecture and young and charming women coexist harmoniously [72].
As these two artworks were created over earlier compositions, the artist had to modify his painting technique. The colour of the ground layer could not be exposed to play the aesthetic role seen in his earlier works; therefore, he executed the paintings with thickly applied paint that covers the entire painting surface.

Outdoor painting and Painting kampong, both from 1954, represent the stylistic innovation of Liu Kang's painting technique, which were emergent in his earlier works, between 1950 and 1953 (Fig. 2a, b). The illusion of depth is entirely abandoned and replaced by a conscious affirmation of the flatness of the forms, which is achieved with solid colours and minimal paint texture. These features reflect the artist's striving toward greater simplicity in his artistic expression and his focus on pure colours. The shapes are enhanced by dark paint outlines as well as exposed white ground, a style that reveals inspiration by the dye-resist technique found in batik textiles (Fig. 18b). Although his new painting technique is stripped of unnecessary details, it required planning and great discipline. A fundamental element of the technique was painting support with a white ground layer.

Reusing earlier compositions for the batik-inspired painting technique produced lower-quality visual effects. In Boats and Char Siew seller, the lack of a white ground was substituted with a white paint applied in a combination of wet-on-wet and wet-on-dry to delineate the forms (Fig. 18c). This approach resulted in less precise divisions between the coloured areas, as the white paint used for the outlines was very often contaminated with pigments of the surrounding colours. Thus, these two artworks lack the freshness and precision that Liu Kang's pure batikinspired paintings are appreciated for. Moreover, utilising the earlier compositions forced the artist to laboriously cover the uneven and already-painted surface, producing unintended impastos and multicolour patches instead of single-colour patches.

Liu Kang was creative in manipulating the paint and painting tools to achieve different artistic effects. His preferred painting tools were varied size brushes. However, in Village, he quickly and effortlessly used a palette knife to apply the paint on large areas, followed by brushwork to introduce some details and outlines (Fig. 18d). Offerings was created primarily with a brush; however, palette knife paint application can be seen on the women's costumes and food stands (Fig. 18e). Heavy impastos appear in Village and in the artworks created on the reused compositions as they required plentiful paint to cover uneven surfaces. However, in Offerings, the impastos play an important role in enhancing the shapes of the fruits as well decorative motifs of the costumes. In Kampong scene, Government office in Johore Bahru and Painting kampong, Liu Kang experimented with distinctive 

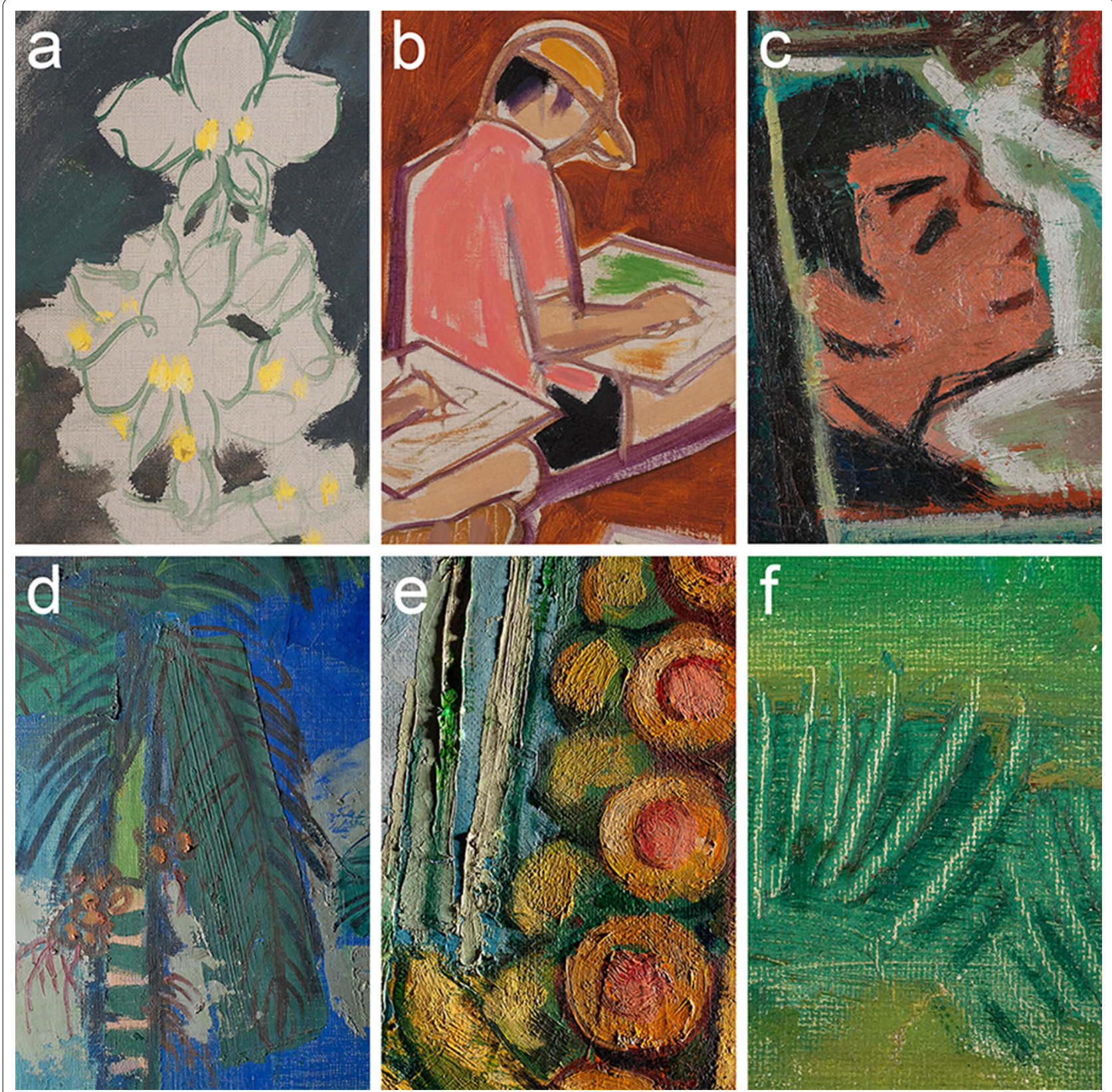

Fig. 18 Details showing intentionally exposed white ground playing a key role in the painting process of: a Orchids; b Outdoor painting. Detail of the white paint application substituting the incorporation of the colour of the ground in the painting process in Char Siew seller (c). Details showing different types of the paint manipulation by the artist. Palette knife and brush application of the paint produced high impastos in Village and Offerings (d, e). Scraping down to the ground reflects the minimalist paint effect in Government office in Johore Bahru (f)

scraping strokes into the wet paint, substituting a descriptive paint application (Fig. 18f).

\section{Artist's modifications and reusing earlier paintings}

Like other artists, Liu Kang occasionally recycled his rejected compositions and painted them over (Table 1). In Offerings, the pronounced brushstrokes that do not correlate to the final composition were observed on the face of the Balinese model on the left-hand side of the painting (Fig. 19a), whereas the evidence of a dark paint layer was discernible through the paint losses of the sky area (Fig. 19b, c). Moreover, a comparison of the painting with its archival photograph, which was probably taken in the 1950s, revealed some alterations to the current 

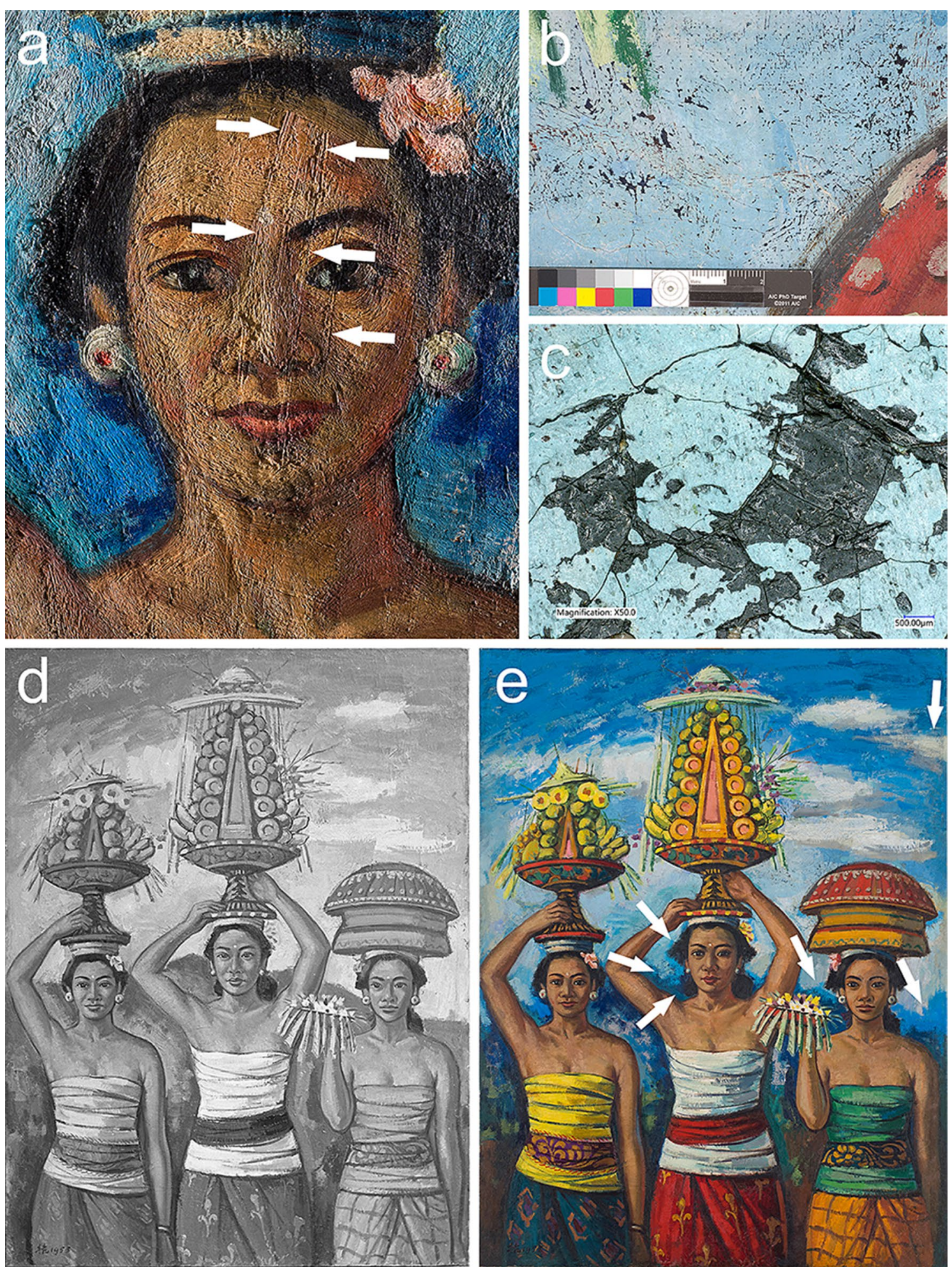

Fig. 19 a Detail of Offerings, showing the brushstrokes corresponding to the earlier composition. b Detail of Offerings revealing dark paint in the sky area. c Digital microscope image of the same area evidencing a dark paint layer scheme, seen through the losses of the current composition. d Archival photograph of Offerings. Liu Kang Family Collection. Image courtesy of Liu family. e Image of the painting showing alterations of the current composition 

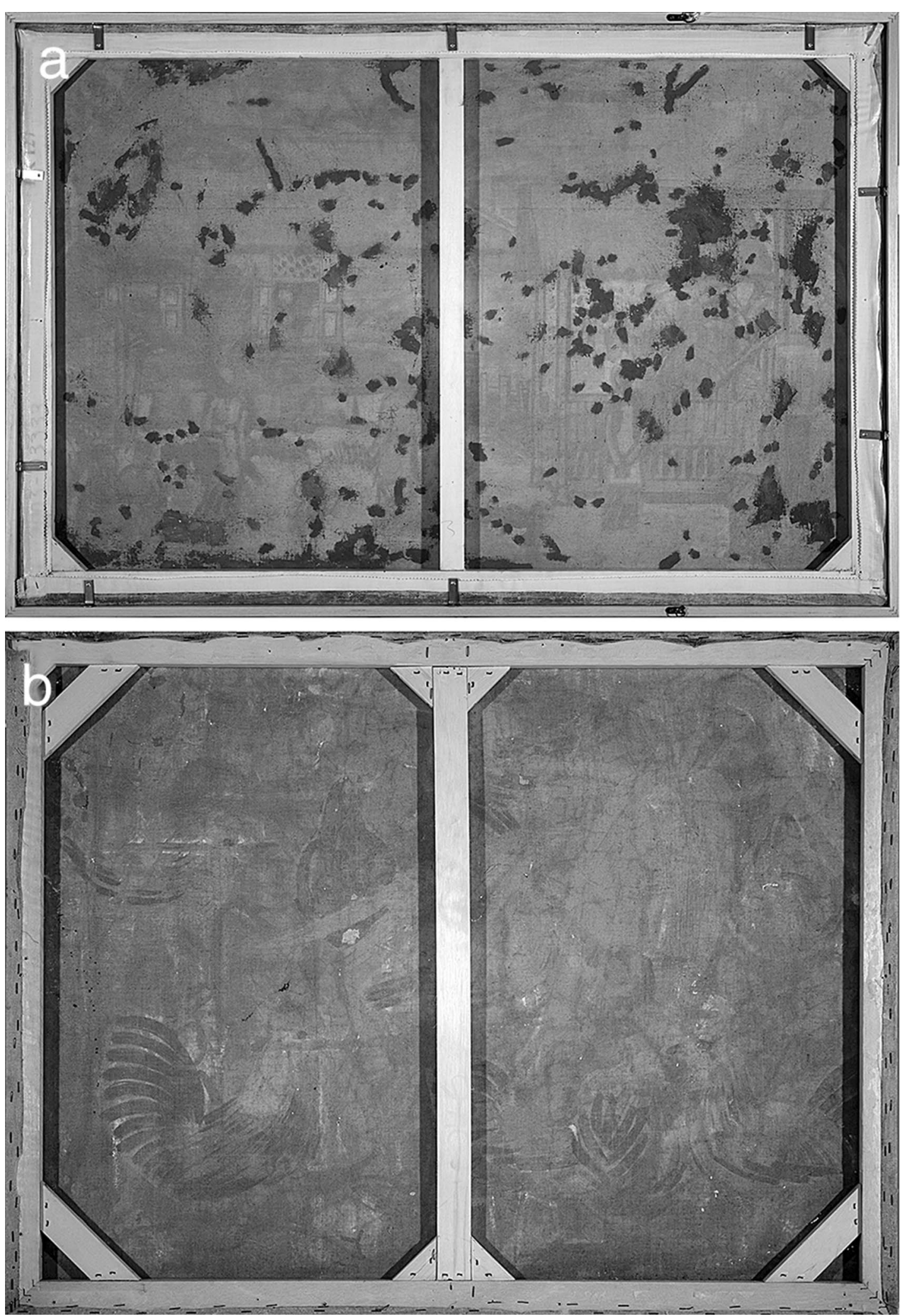

Fig. 20 IR images of the reverse sides of $\mathbf{a}$ Scene in Bali rotated at $90^{\circ}$ clockwise; $\mathbf{b}$ Boats rotated at $90^{\circ}$ anticlockwise 

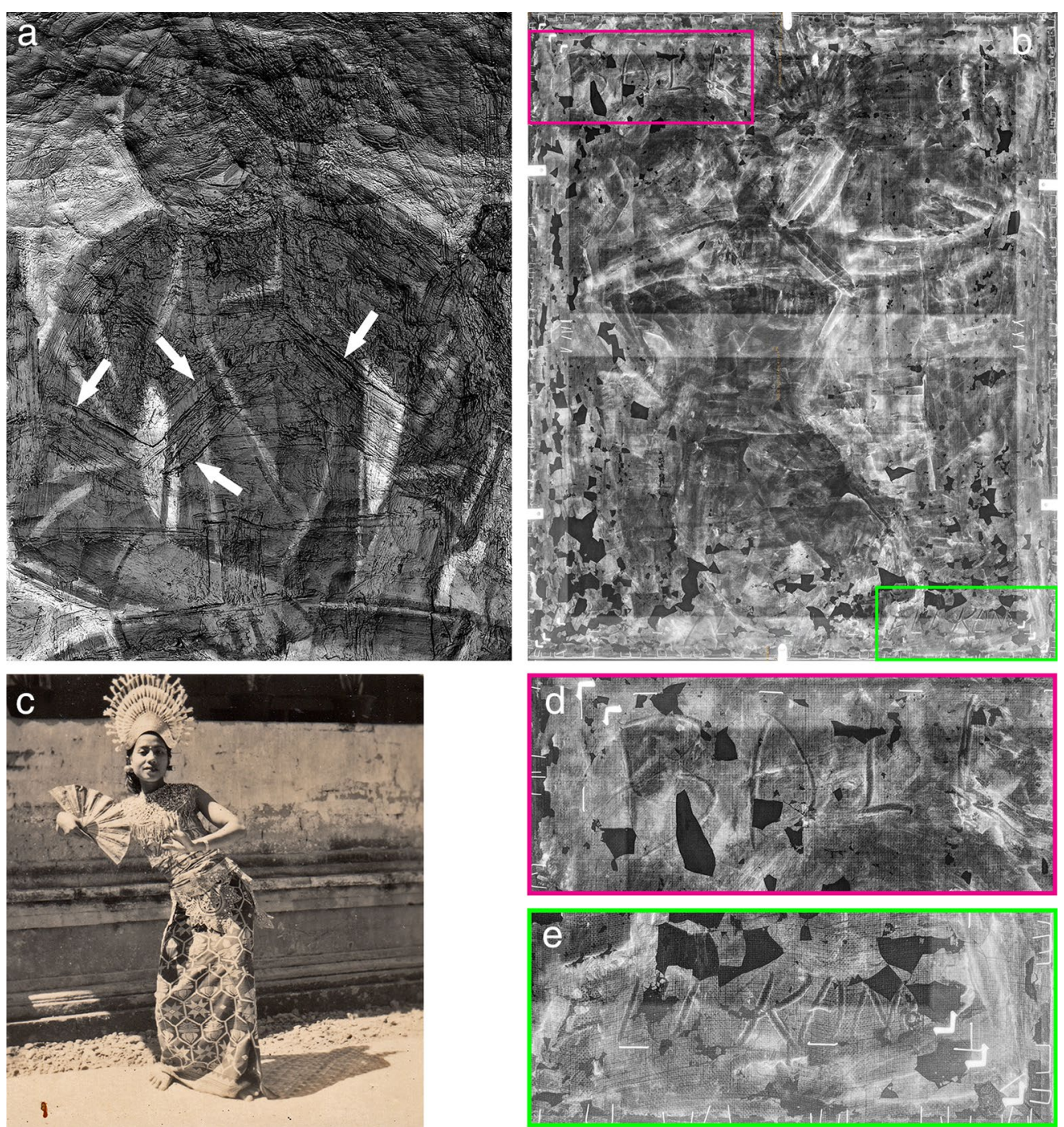

Fig. 21 a RTI detail image of Char Siew seller, revealing texture details corresponding to the earlier painted composition. $\mathbf{b}$ XRR image of the painting rotated at $90^{\circ}$ clockwise, unveiling a vertical composition of a dancer. $\mathbf{c}$ Archival photograph of a Balinese dancer taken by the artist. Liu Kang Family Collection. Image courtesy of Liu family. d, e XRR detail images of the painting showing an inscription (BALI) and a signature (LIU KANG)

composition. The changes are located in the central model's face and hairstyle and in the shape of the distant hilltops and clouds (Fig. 19d, e). As the painting was donated by Liu Kang in 2003, these alterations can be attributed to him. This finding confirms the artist's tendency to rework the paintings after their creation, which can cause art-historical implications $[15,36]$.

The IR photography of the reverse sides of the paintings was very effective in detecting the concealed compositions. Thus, a composition created in the horizontal orientation resembling the village scene was found underneath Scene in Bali. The IR imaging technique allowed us to identify typical Malay timber houses, characterised by verandahs with fretwork railing panels and perforated ventilation panels fitted above the doors or upper sections of the walls (Fig. 20a) [73, 74], similar to those in Liu Kang's Village and Kampong scene (Fig. 1a, b). Another horizontally oriented composition was found underneath Boats. The hidden scene depicts a group of farm animals, including what appears to be cattle, surrounded by chickens and other animals in the foreground (Fig. 20b).

The evidence of an earlier composition underneath Char Siew seller was initially discovered with RTI. In several areas, the pronounced underlying brushstrokes do not accord with the current composition (Fig. 21a). The XRR revealed a hidden vertical composition of a Balinese dancer that could have been inspired by one of the 
photographs taken by the artist (Fig. 21b, c). The discovery of this composition is especially interesting because the artist made an inscription (BALI) in the top-left corner and signature (LIU KANG) in the bottom-right corner of the painting by scratching into wet paint with a sharp tool (Fig. 21d, e). Interestingly, XRR showed extensive losses to the paint layer, which could have encouraged the artist to abandon the composition and reuse the canvas.

\section{Conclusions}

The extensive technical study was carried out on ten paintings, which represent Liu Kang's important period of the 1950s when he developed his own style [75]. The study combined non- and micro-invasive analytical methods to characterise the artist's painting materials and technique. The yield results were cross-referenced with the single source indicating Liu Kang's pigment preferences during the investigated period. The limitations of that source were compensated by referencing contemporary advertisements that indicate some artists' colourmen brands available in Singapore around that time. Accessing their catalogues was an important step to better interpret certain data derived from the analyses. The understanding of Liu Kang's working practice was advanced by his archival drawings and old photographs.

The results show continuous use of the majority of the identified painting materials during the periods before the trip to Indonesia (1950-1952) and after (1953-1958). The study revealed that the artist used commercially prepared linen canvases, which he probably purchased in lengths by the metre. Although four canvas densities and five types of ground preparation were distinguished, Liu Kang's preferred type of support was linen canvas with a thread count of $13 \times 15$ per $\mathrm{cm}$ and a double-layered oil-based ground. Both layers are composed of the same constituents (chalk, lithopone and/or barium white and zinc white, lead white and titanium white), albeit mixed in different concentrations. This type of painting support was identified in the artworks created before and after 1952. Single- and, exceptionally, triple-layered structure of ground as well as semi-absorbent ground on canvases with distinctively low and high densities were used less frequently.

With regard to the palette of colours, all investigated pigment mixtures were bound in oil. Ultramarine appears consistently in the blue passages with occurrences of Prussian, cerulean, cobalt, phthalocyanine and manganese blues. However, cerulean and cobalt blues appear only in Government office in Johore Bahru (1953), manganese blue was used only in Scene in Bali (1953), and phthalocyanine blue was the sole blue pigment employed in Painting kampong (1954). As for green paints, viridian was used predominantly but always in mixes with other pigments. Its frequent presence with cadmium yellow and/or zinc yellow does not rule out the use of commercially prepared cadmium green or permanent green. Other green pigments used intermittently are phthalocyanine green and emerald green. Emerald green was identified in two paintings, Village (1950) and Orchids (1952), whereas phthalocyanine green appears in Char Siew seller (1958). Green colours were also obtained by mixing Prussian blue and/or ultramarine with $\mathrm{Cd}$ - and $\mathrm{Cr}$-containing yellows. Regarding the yellow paints, it is clearly evident from the analytical data that cadmium yellow or its variant was prevailing. Other detected yellow pigments are yellow iron oxide, chrome, zinc and cobalt yellows. For obtaining brown paints, Liu Kang used yellow and red iron oxides and umber, and sometimes modified them with $\mathrm{Cr}$-containing yellow(s), cadmium yellow or its variant and bone black. The analyses of the red paints revealed that Liu Kang made an extensive use of organic red pigments. Although identifying the organic reds was challenging, evidence suggests eosin-derived geranium lake, anthraquinone derivative pigment synthetic alizarin lake, and red azo pigment naphthol red AS-D. There is also a notable presence of cadmium red. Regarding white paints, the use of lead white, lithopone and/or barium white and zinc white was confirmed. Black painted areas contain bone black and its occurrences were found in mixtures with other pigments. The obtained results of the pigments' analyses do not fully corroborate Ho Kok Hoe's 1955 account about Liu Kang's paints. Except for viridian, which was confirmed as the artist's favourite green, it is evident that Prussian blue is not the prevailing 
blue pigment; however, it was extensively used as an admixture for green paints. Vermilion was not identified in the investigated paint samples. Nevertheless, it is conceivable that Liu Kang, while sharing the information with Ho Kok Hoe, referred to a composite pigment sold under a similar name and containing organic and inorganic pigments.

The studies of Liu Kang's painting process revealed a distinctive conceptual phase represented by the consistent use of drawings and photographs, which appear to be a convenient method of capturing interesting subjects and motifs for future reference. This phase helped the artist to grasp a full idea of the intended painting, hence resulting in a minimal need for preparatory drawing on the primed canvas. The analyses of the painting technique allowed us to identify four different approaches, suggesting an evolution of the methods of expression that were finalised in the stylistic innovation seen in Outdoor painting and Painting kampong. His painting technique, which reveals an effortless manipulation of the paint with a brush and palette knife, benefits from thorough studies of the idea prior to the painting. His repertory of descriptive techniques includes scraping into wet paint, building the impastos, enhancing the shapes with outlines and exposing the white ground of the canvas. An important contribution to the knowledge of Liu Kang's working practice was evidencing the modifications he made during the painting and detecting the rejected compositions he reused for new artworks.

Finally, the low concentrations of the investigated pigments in the heterogeneous structures of the paint layers made the identification process a challenging one. Thus, the findings of the analysis mandate a broader characterisation of Liu Kang's pigments, which require the application of chromatography and a range of vibrational spectroscopic techniques. Besides mapping the distribution of the painting materials, macro X-ray fluorescence (MA-XRF) imaging could also assist in a better visualisation of the concealed compositions. 


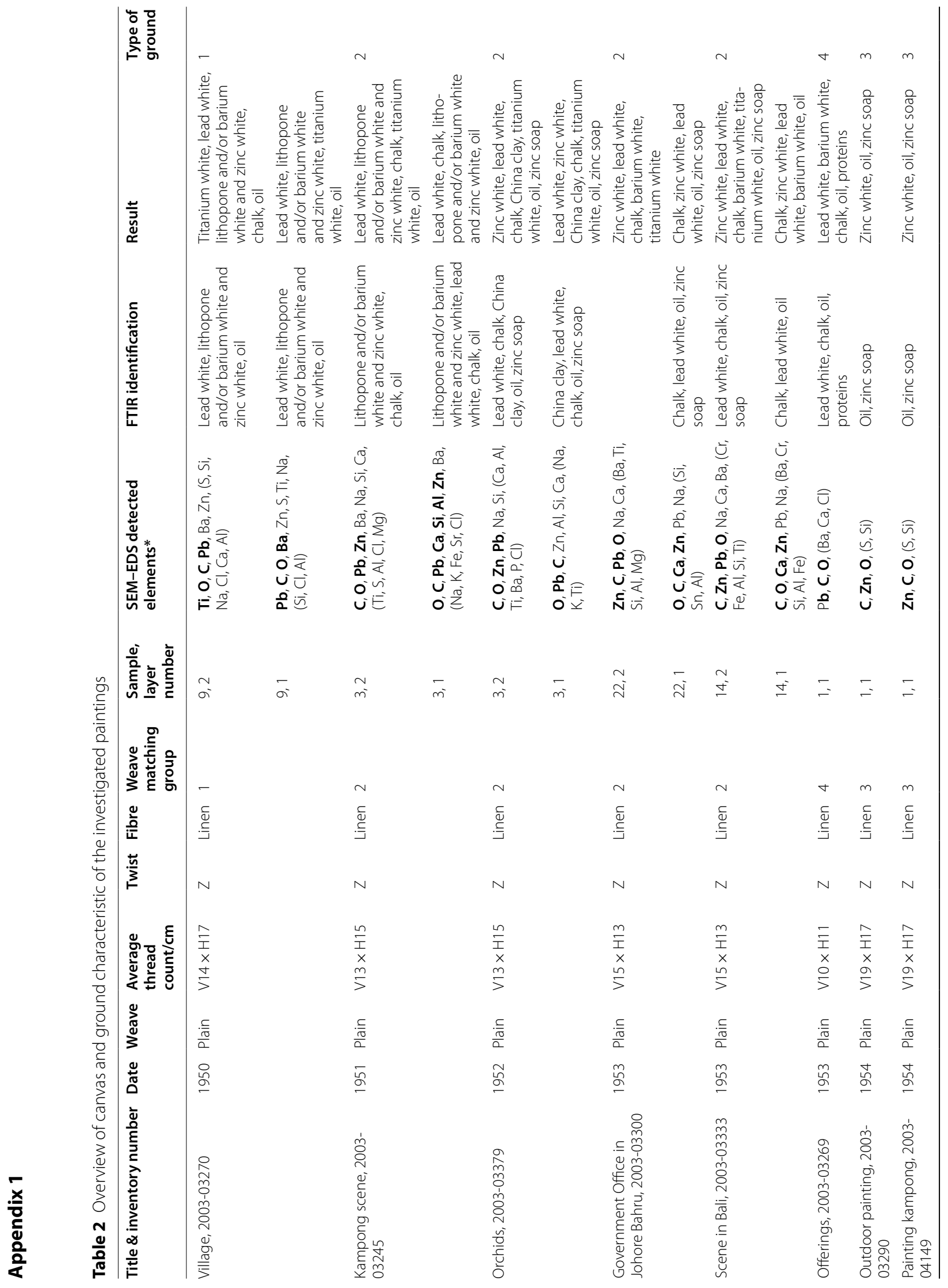




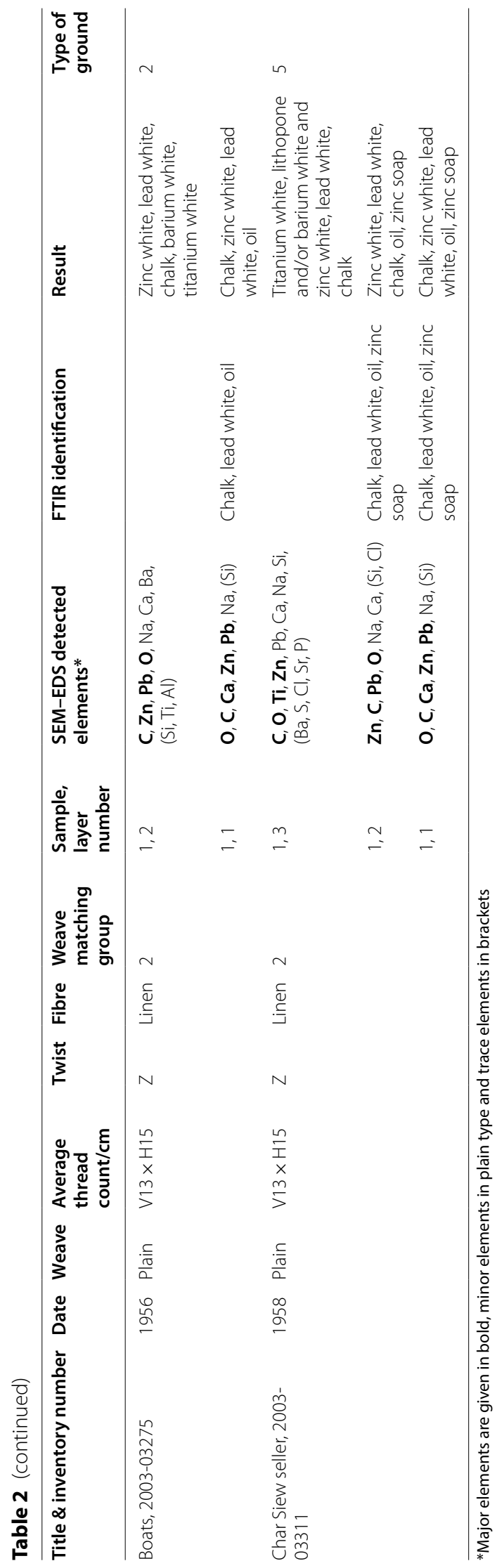




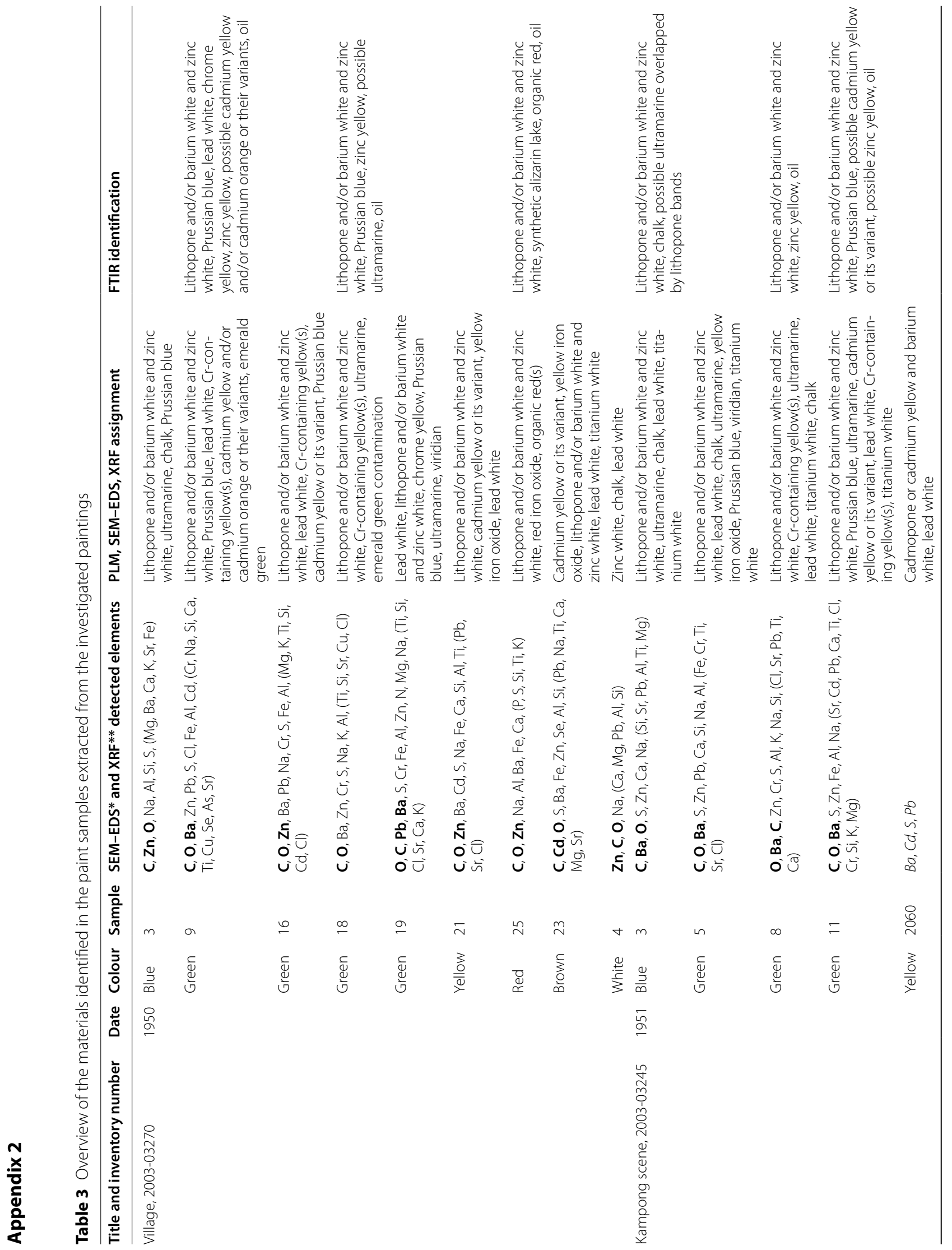




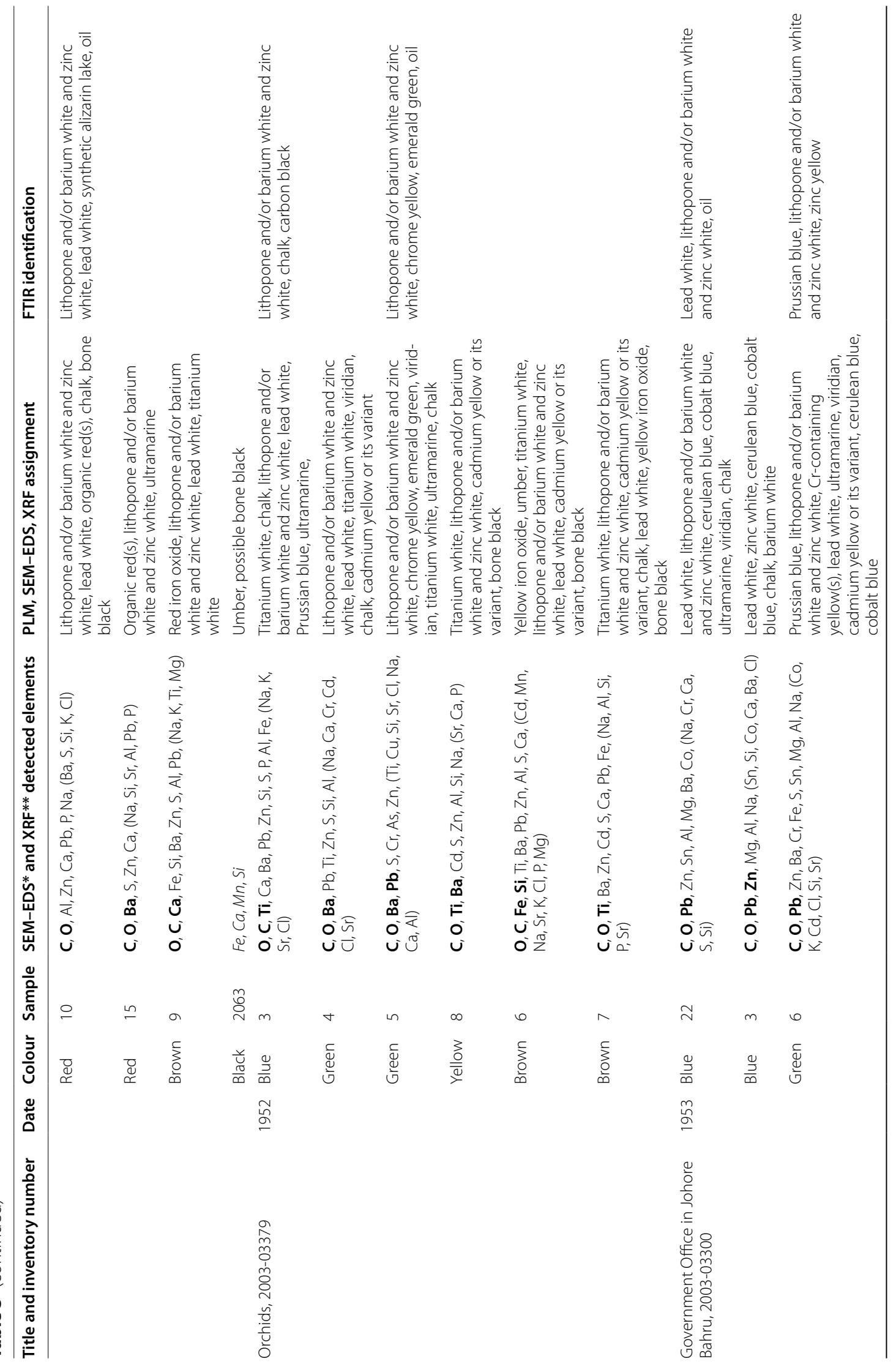




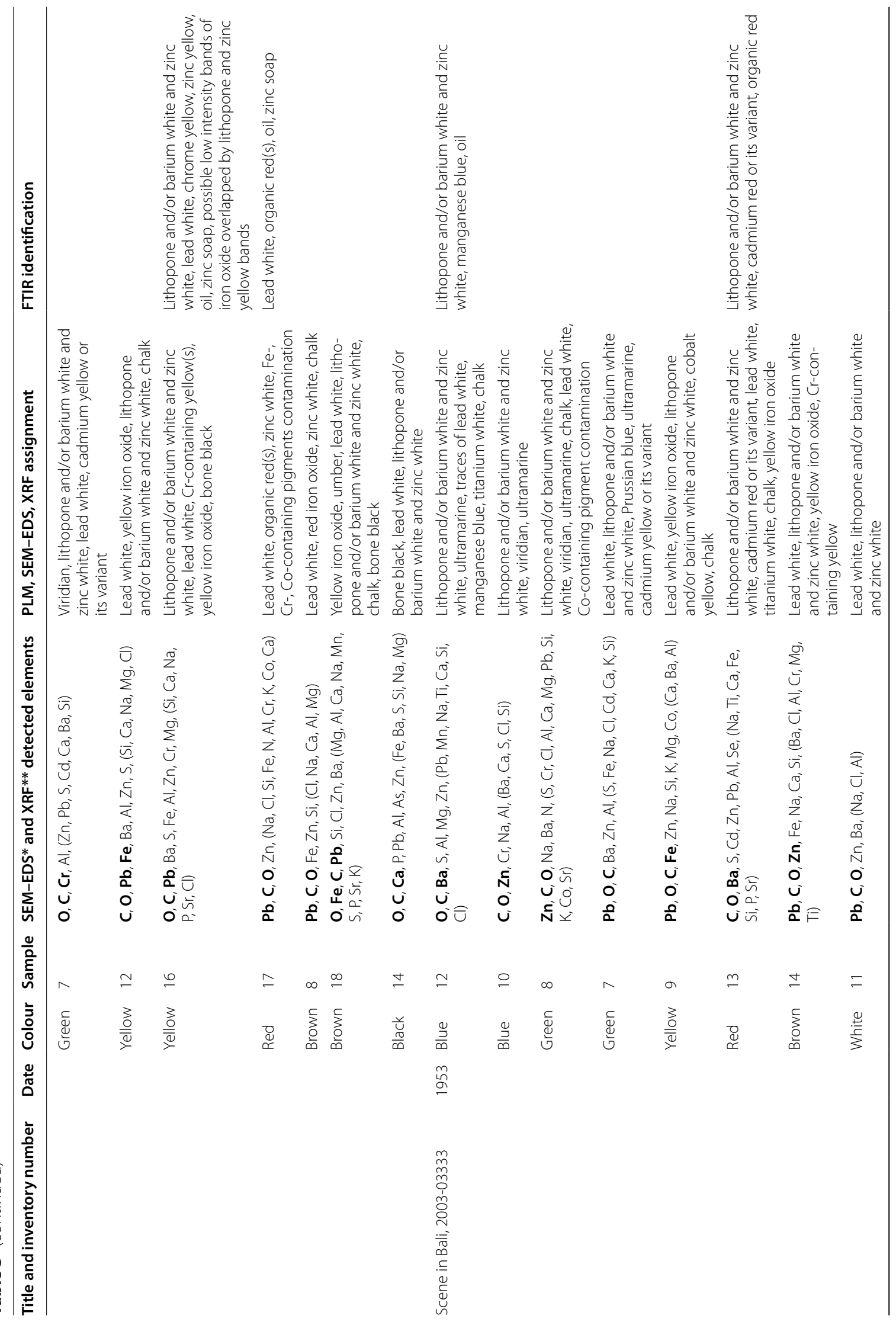




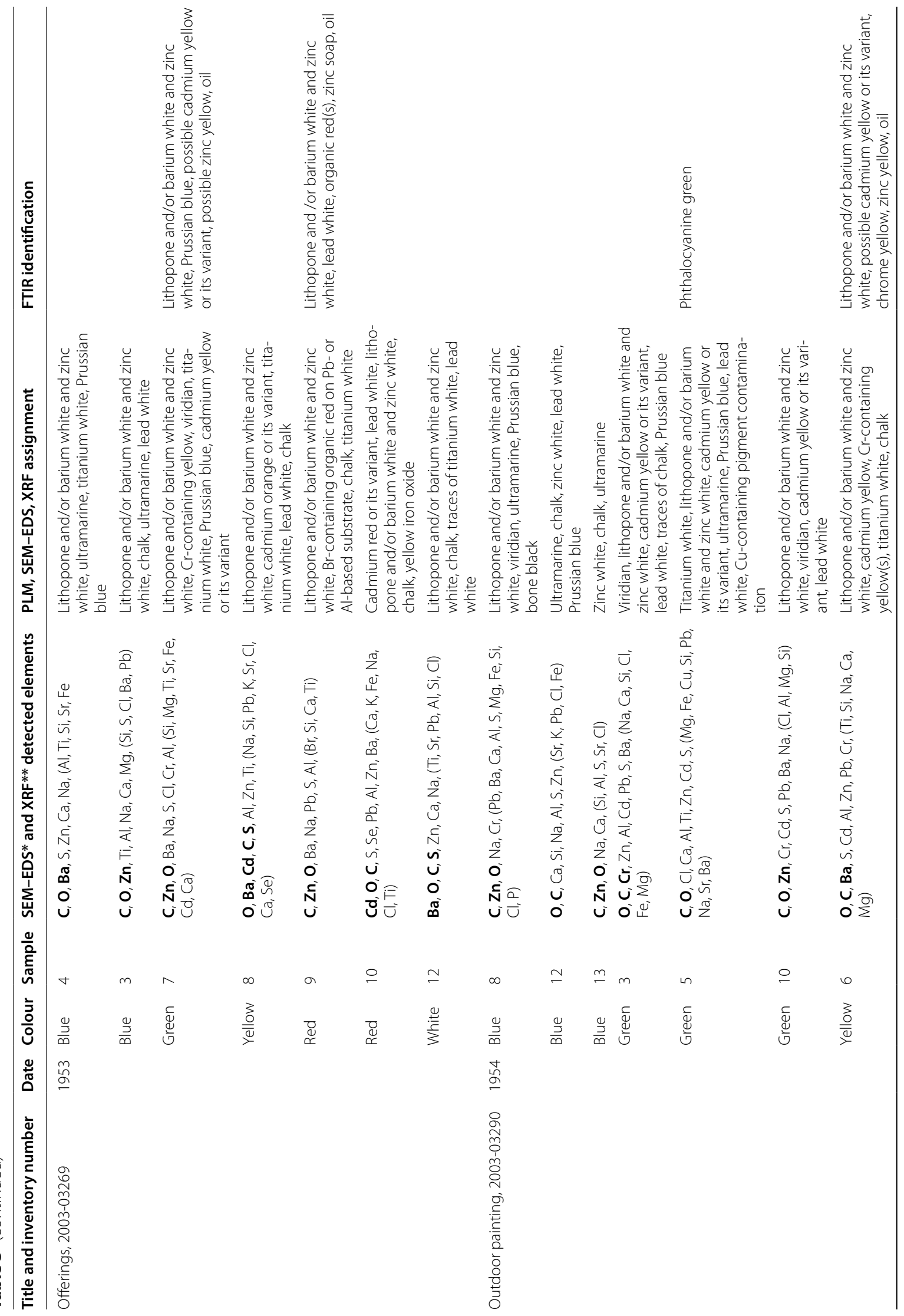




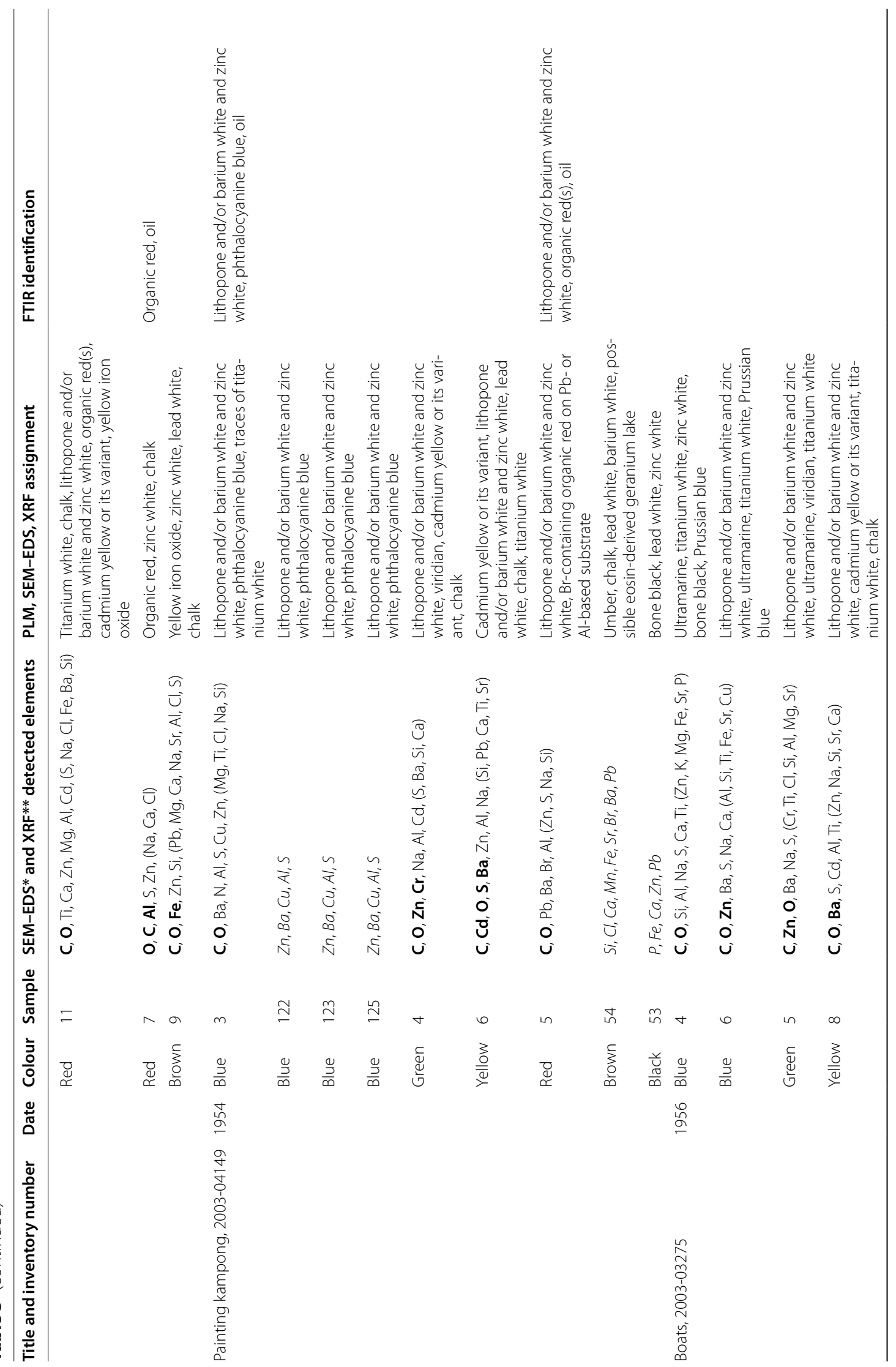




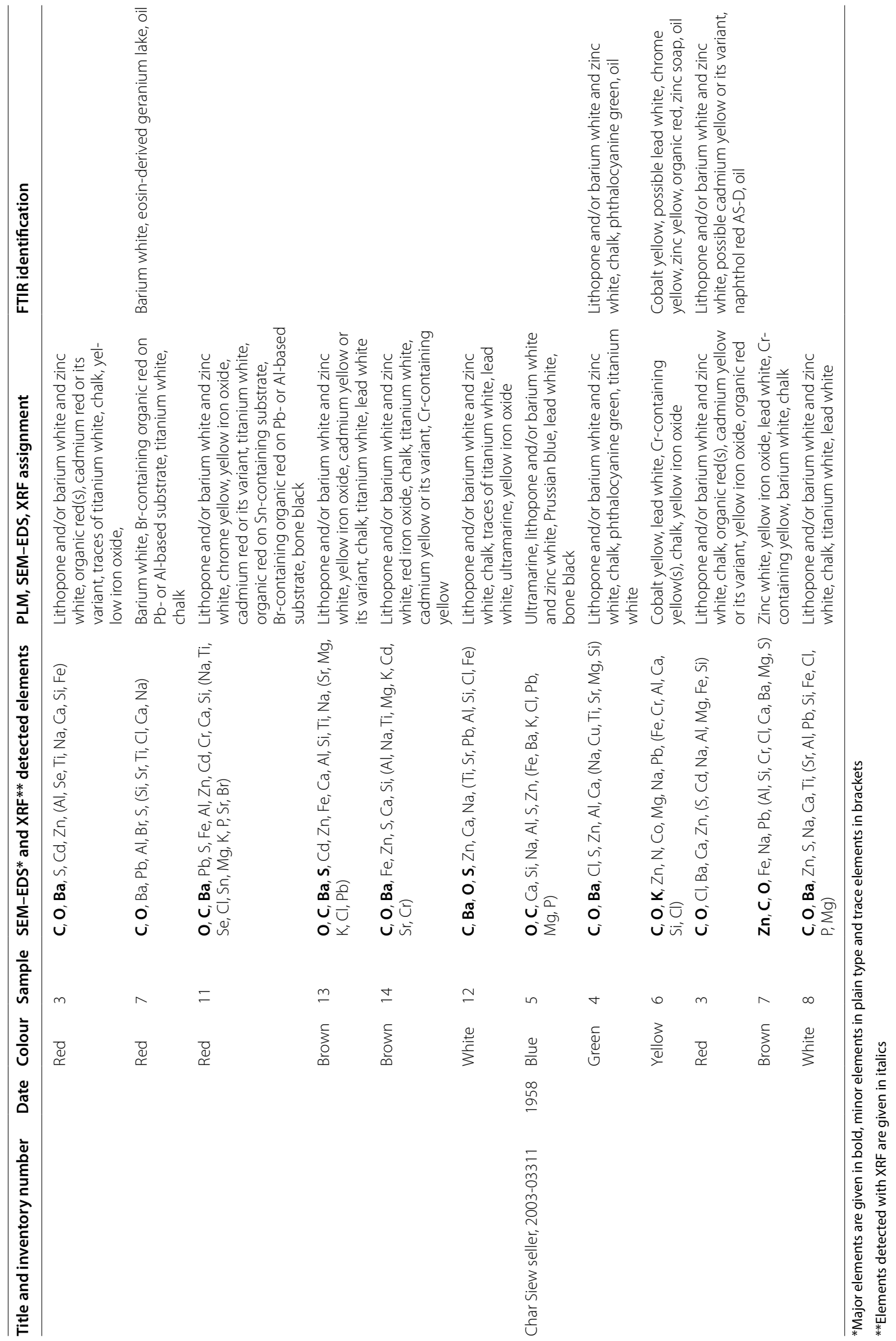




\section{Abbreviations}

NGS: National Gallery Singapore; UVF: Ultraviolet fluorescence; UVR: Reflected ultraviolet; IR: Infrared; IRFC: Infrared false-colour; RTI: Reflectance transformation imaging; XRR: X-ray radiography; XRF: X-ray fluorescence; OM: Optical microscopy; PLM: Polarised light microscopy; FE-SEM-EDS: Field emission scanning electron microscope with energy dispersive spectroscopy; BSE: Backscattered electron mode; ATR-FTIR: Attenuated total reflectance-Fourier transform infrared spectroscopy; MA-XRF: Macro X-ray fluorescence; W\&N: Winsor \& Newton; R\&S: Reeves \& Sons.

\section{Acknowledgements}

The authors would like to acknowledge the National Gallery Singapore for providing paintings for analyses; Gretchen Liu for sharing the artist's family archives; the Heritage Conservation Centre for supporting this research. The authors would like to thank Hanna Szczepanowska at West Virginia University for helpful suggestions related to the improvement of this article; Roger Lee (Assistant Painting Conservator from the Heritage Conservation Centre) for his tireless dedication to the RTI acquisition; Kenneth Yeo Chye Whatt (Principal Radiographer from the Division of Radiological Sciences at the Singapore General Hospital); and Steven Wong Bak Siew (Head and Senior Consultant from the Department of Radiology at the Sengkang General Hospital) for enabling the $\mathrm{X}$-ray radiography. We also gratefully acknowledge the reviewers for kindly reviewing this article.

\section{Authors' contributions}

$\mathrm{DL}$ carried out the examination of the paintings, technical photography, RTI, sampling, OM, PLM, XRF, SEM-EDS analyses, data interpretation, and wrote the manuscript. TK provided the interpretation of the FTIR data. MM carried out the FTIR analyses. BS carried out the FTIR analyses and provided visualisation of the FTIR data. All authors read and approved the final manuscript.

\section{Funding}

Not applicable.

\section{Availability of data and materials}

The datasets generated and/or analysed during the current study are available from the corresponding author on reasonable request.

\section{Declarations}

\section{Competing interests}

Authors declare that have no competing interests.

\begin{abstract}
Author details
${ }^{1}$ Heritage Conservation Centre, National Heritage Board, 32 Jurong Port Rd, 619104 Singapore, Republic of Singapore. ${ }^{2}$ Department of Painting Technology and Techniques, Institute for Conservation, Restoration and Study of Cultural Heritage, Nicolaus Copernicus University, ul. Sienkiewicza 30/32, 87-100 Toruń, Poland. ${ }^{3}$ Department of Telecommunications and Teleinformatics, Wrocław University of Science and Technology, Wybrzeże Stanisława Wyspiańskiego 27, 50-370 Wrocław, Poland.
\end{abstract}

Received: 31 October 2021 Accepted: 28 December 2021 Published online: 28 January 2022

\section{References}

1. Wai Hon C. Liu Kang at 87. In: Han Wue T, editor. Liu Kang at 87. Singapore: National Arts Council, National Heritage Board; 1997. p. 19.

2. The encyclopedia of the Chinese overseas. Singapore: Archipelago Press, Landmark Books; 2006. p. 16.

3. Low SW. Introduction to exhibition. Convergences: Chen Wen Hsi centennial exhibition. Singapore: Singapore Art Museum; 2009. p. 28-29.

4. Sabapathy TK. The Nanyang artists: some general remarks. Pameran retrospektif pelukis-pelukis Nanyang. Muzium Seni Negara Malaysia, 26hb Oktober-23hb Disember 1979. Kuala Lumpur: Muzium Seni Negara Malaysia; 1979. p. 44.
5. Sabapathy TK. Forty years and after: the Nanyang artists. Remarks on art and history. In: Thang KH, editor. New directions 1980-1987: modern paintings in Singapore. Singapore: Horizon Publishing; 1987. p. 4.

6. Ong E. The Nanyang artists: eclectic expressions of the South Seas. In: Khairuddin NH, Yong B, Sabapathy TK, editors. Imagining identities: narratives in Malaysian art. Kuala Lumpur: Rogue Art; 2012. p. 63, 64, 65, 66.

7. Tan MK. The evolution of the Nanyang art style: a study in the search for an artistic identity in Singapore, 1930-1960 [Master's thesis]. Hong Kong: Hong Kong University of Science and Technology; 1997. p. 42, 116. http:// hdl.handle.net/1783.1/4804. Accessed 18 Apr 2021.

8. Chung A. Traditions and the modernitst vision: Chinese paintings of Chen Wen Hsi. Convergences. Chen Wen Hsi centennial exhibition. Singapore: Singapore Art Museum; 2006. p. 190.

9. Lim HT. Preface. The art of young Malayans. Singapore: Nanyang Academy of Fine Arts; 1955. p. 1.

10. Sabapathy TK. Hak Tai points the way. The Straits Times: 198128 February; p. 7. http://eresources.nlb.gov.sg/newspapers/Digitised/Article/straitstim es19810228-1.2.114.13.1. Accessed 18 Apr 2021.

11. Liu K. I am eighty-seven. In: Han Wue T, editor. Liu Kang at 87. Singapore: National Arts Council, National Heritage Board; 1997. p. 28, 29.

12. Long TS. Nanyang style and the French influence. Pont des Arts: Nanyang artists in Paris, 1925-1970. Singapore: Singapore Art Museum; 1994. p. 32.

13. Nyen HT. Afterimages: strands of modern art in Singapore [Master's thesis]. Singapore: National University of Singapore; 2008. p. 229. http:// scholarbank.nus.edu.sg/handle/10635/13280. Accessed 18 Apr 2021.

14. Seng YJ. Lim Hak Tai points a third way: towards a socially engaged art by the Nanyang artists, 1950s-1960s. In: Low SW, Flores PD, editors. Charting thoughts: essays on art in southeast Asia. Singapore: National Gallery Singapore; 2017. p. 195.

15. Lizun D, Kurkiewicz T, Szczupak B. Exploring Liu Kang's Paris practice (1929-1932): insight into painting materials and technique. Heritage. 2021;4(2):828-63. https://doi.org/10.3390/heritage4020046.

16. Lizun D, Kurkiewicz T, Szczupak B. Technical examination of Liu Kang's Paris and Shanghai painting supports (1929-1937). Herit Sci. 2021;9(1):37. https://doi.org/10.1186/s40494-021-00492-6.

17. Rawanchaikul T. Nanyang art and otherness. Liu Kang-tropical vanguard. In: Proceedings from a forum commemorating the centennial year of Liu Kang's birth (1911-2011). Singapore: Innovation Fund Limited; 2011. p. 18-21.

18. Cosentino A. Identification of pigments by multispectral imaging; a flowchart method. Herit Sci. 2014;2(1):12. https://doi.org/10.1186/ 2050-7445-2-8

19. Cosentino A. Practical notes on ultraviolet technical photography for art examination. Conserv Patrim. 2015. https://doi.org/10.14568/cp2015006.

20. Cosentino A. Infrared technical photography for art examination. e-Preserv Sci. 2016;13:1-6.

21. Warda J, Frey F, Heller D, Kushel D, Vitale T, Weaver G. The AIC guide to digital photography and conservation documentation. Washington, D.C.: American Institute for Conservation of Historic and Artistic Works; 2011.

22. Schroer C, Bogart J, Mudge B, Lum M. Guide to highlight image capture. Cultural Heritage Imaging. 2013. http://culturalheritageimaging.org/ What_We_Offer/Downloads/RTI_HIt_Capture_Guide_v2_0.pdf. Accessed 27 Mar 2021.

23. Schroer C, Bogart J, Mudge B, Lum M. Guide to highlight image processing. Cultural Heritage Imaging. 2011. http://culturalheritageimaging.org/ What_We_Offer/Downloads/rtibuilder/RTI_hlt_Processing_Guide_v14_ beta.pdf. Accessed 27 Mar 2021.

24. Schroer C, Bogart J, Mudge B, Lum M. Guide to RTIViewer. Cultural Heritage Imaging. 2013. http://culturalheritageimaging.org/What_We_Offer/ Downloads/rtiviewer/RTIViewer_Guide_v1_1.pdf. Accessed 27 Mar 2021.

25. Mactaggart P, Mactaggart A. A pigment microscopist's notebook. Chard: Mactaggart; 1998.

26. Odegaard N, Carroll S, Zimmt WS. Material characterization tests for objects of art and archaeology. London: Archetype publications; 2000.

27. Price BA, Pretzel B, Lomax SQ. Infrared and Raman Users Group spectral database. Philadelphia: Infrared and Raman Users Group; 2007. http:// www.irug.org. Accessed 20 Dec 2021.

28. Sandu ICA, Luca C, Sandu I, Vasilache V, Hayashi M. Authentication of the ancient easel paintings through materials identification from the polychrome layers II. Analysis by means of the FT-IR spectrophotometry. Rev Chim. 2008;59(4):384-7. https://doi.org/10.37358/RC.08.4.1792. 
29. Otero V, Sanches D, Montagner C, Vilarigues M, Carlyle L, Lopes JA, et al. Characterisation of metal carboxylates by Raman and infrared spectroscopy in works of art. J Raman Spectrosc. 2014;45(11-12):1197-206. https://doi.org/10.1002/jrs.4520.

30. Cotte M, Checroun E, Susini J, Walter P. Micro-analytical study of interactions between oil and lead compounds in paintings. Appl Phys A. 2007;89(4):841-8. https://doi.org/10.1007/s00339-007-4213-4

31. Robinet $L$, Corbeil-a M-C. The characterization of metal soaps. Stud Conserv. 2003;48(1):23-40. https://doi.org/10.1179/sic.2003.48.1.23.

32. Tse N, Sloggett R. Southeast Asian oil paintings: supports and preparatory layers. In: Townsend J, Doherty T, Heydenreich G, Ridge J, editors. Preparation for painting: the artist's choice and its consequence. London: Archetype Publications; 2008. p. 153.

33. Malayan Trade Directory 1949-1952. Singapore: M Sinn; 1950. p. 462.

34. E.J. Motiwalla \& Co. Malaya tribune: advertisement. 1950 December 11; p. 18. http://eresources.nlb.gov.sg/newspapers/Digitised/Article/maltribune 19501211-1.2.139.1. Accessed 18 Apr 2021.

35. The Shanghai Book Company. The Singapore Free Press: advertisement. 1951 December 15; p. 4. http://eresources.nlb.gov.sg/newspapers/Digit ised/Article/freepress19511215-1.2.121.25.1. Accessed 18 Apr 2021.

36. Lizun D. From Paris and Shanghai to Singapore: a multidisciplinary study in evaluating the provenance and dating of two of Liu Kang's paintings. J Conserv Sci. 2021;37(4):322-39. https://doi.org/10.12654/JCS.2021.37.4. 02.

37. Talens advertisement. The Singapore artist. 1955;1(3).

38. Harley RD. Artists' prepared canvases from Winsor \& Newton 1928-1951. Stud Conserv. 1987;32(2):77-85. https://doi.org/10.1179/sic.1987.32.2.77.

39. Yow SK. Liu Kang, photography and Chinese Modernism. In: Yeo WW, editor. Liu Kang: colourful modernist. Singapore: National Art Gallery; 2011. p. 134.

40. Hoe HK. Liu Kang. The Singapore artist. 1955;1(3):16.

41. Lizun D. A preliminary study of Liu Kang's palette and the discovery and interpretation of hidden paint layers. Herit Sci. 2020;8(1):21. https://doi. org/10.1186/s40494-020-0363-x.

42. Lizun D, Szroeder P, Kurkiewicz T, Szczupak B. Examination of painting technique and materials of Liu Kang's Seafood and hidden self-portrait. Int J Conserv Sci. 2021;12(1):3-26.

43. de Queiroz Baddini AL, de Paula Santos JLV, Tavares RR, de Paula LS, da Costa Araújo Filho H, Freitas RP. PLS-DA and data fusion of visible Reflectance, XRF and FTIR spectroscopy in the classification of mixed historical pigments. Spectrochim Acta A. 2022;265:1-9. https://doi.org/10.1016/j. saa.2021.120384.

44. Defeyt C, Strivay D. PB15 as 20th and 21st artists' pigments: conservation concerns. e-Preserv Sci. 2014;11:6-14.

45. Lv D, Sung H-S, Li X, Zhang X, Li Z, Chen D. Effects of single layer graphene and graphene oxide modification on the properties of phthalocyanine blue pigments. Dyes Pigm. 2020;180:1-11. https://doi.org/10. 1016/j.dyepig.2020.108449.

46. Buti D, Rosi F, Brunetti BG, Miliani C. In-situ identification of copperbased green pigments on paintings and manuscripts by reflection FTIR. Anal Bioanal Chem. 2013;405(8):2699-711. https://doi.org/10.1007/ s00216-013-6707-6.

47. Tate Gallery. IOD00493, Pigment Green 7 (PG7). In: Infrared and Raman Users Group spectral database. Philadelphia: Infrared and Raman Users Group; 2007. http://irug.org/jcamp-details?id=572. Accessed 20 Dec 2021.

48. Lomax SQ. Phthalocyanine and quinacridone pigments: their history, properties and use. Stud Conserv. 2005;50(sup1):19-29. https://doi.org/ 10.1179/sic.2005.50.Supplement-1.19.

49. Fiedler I, Bayard MA. Cadmium yellows, oranges and reds. In: Feller RL, editor. Artists' pigments: a handbook of their history and characteristics. Washington: National Gallery of Art; 1986. p. 65, 74, 80.

50. Eastaugh N, Walsh V, Chaplin T, Siddall R. Pigment compendium: a dictionary and optical microscopy of historical pigments. London: Butterworth-Heinemann; 2008. p. 17, 74, 157, 173, 393.

51. Simonsen KP, Christiansen MB, Vinum MG, Sanyova J, Bendix J. Single crystal X-ray structure of the artists' pigment zinc yellow. J Mol Struct. 2017;1141:322-7. https://doi.org/10.1016/j.molstruc.2017.03.108.

52. Kühn H, Curran M. Chrome yellow and other chromate pigments. In: Feller RL, editor. Artists' pigments: a handbook of their history and characteristics. Washington: National Gallery of Art; 1986. p. 201.
53. Getty Conservation Institute. IMP00028, Pigment Yellow 40 (PY40). In: Infrared and Raman Users Group spectral database. Philadelphia: Infrared and Raman Users Group; 2007. http://irug.org/jcamp-details?id=476. Accessed 20 Dec 2021.

54. Centeno SA, Hale C, Carò F, Cesaratto A, Shibayama N, Delaney J, et al. Van Gogh's Irises and roses: the contribution of chemical analyses and imaging to the assessment of color changes in the red lake pigments. Herit Sci. 2017;5(1):18. https://doi.org/10.1186/s40494-017-0131-8.

55. Geldof M, de Keijzer M, van Bommel M, Pilz K, Salvant J, van Keulen $H$, et al. Van Gogh's geranium lake. In: Jansen L, Geldof M, Haswell R, Hendriks E, van Heugten S, editors., et al., Van Gogh's studio practice. New Haven: Yale University Press; 2013. p. 268-89.

56. Ghelardi E, Degano I, Colombini MP, Mazurek J, Schilling M, Learner T. Py-GC/MS applied to the analysis of synthetic organic pigments: characterization and identification in paint samples. Anal Bioanal Chem. 2015;407(5):1415-31. https://doi.org/10.1007/s00216-014-8370-y.

57. Fieberg JE, Knutås P, Hostettler K, Smith GD. "Paintings fade like flowers": pigment analysis and digital reconstruction of a faded pink lake pigment in Vincent van Gogh's Undergrowth with two figures. Appl Spectrosc. 2017;71(5):794-808. https://doi.org/10.1177/0003702816685097.

58. Kirby J. The reconstruction of late 19th-century French red lake pigments. In: Clarke M, Townsend J, Stijnman A, editors. Art of the past: sources and reconstruction: proceedings of the first symposium of the Art Technological Source Research study group. London: Archetype Publications, ICN Amsterdam; 2005. p. 75.

59. de Keijzer M, van Bommel M. Bright new colours: the history and analysis of fluorescein, eosin, erythrosine, rhodamine and some of their derivatives. In: Kirby J, editor. The diversity of dyes in history and archaeology. London: Archetype Publications; 2017. p. 326-38.

60. Pozzi F, Basso E, Centeno SA, Smieska LM, Shibayama N, Berns R, et al. Altered identity: fleeting colors and obscured surfaces in Van Gogh's Landscapes in Paris, Arles, and Saint-Rémy. Herit Sci. 2021;9(1):15. https:// doi.org/10.1186/s40494-021-00489-1.

61. Anselmi C, Capitani D, Tintaru A, Doherty B, Sgamellotti A, Miliani C. Beyond the color: a structural insight to eosin-based lakes. Dyes Pigm. 2017;140:297-311. https://doi.org/10.1016/j.dyepig.2017.01.046.

62. Sabatini F, Eis E, Degano I, Thoury M, Bonaduce I, Lluveras-Tenorio A. The issue of eosin fading: a combined spectroscopic and mass spectrometric approach applied to historical lakes. Dyes Pigm. 2020;180:1-12. https:// doi.org/10.1016/j.dyepig.2020.108436.

63. Kirby J, Spring M, Higgitt C. The technology of red lake pigment manufacture: study of the dyestuff substrate. Natl Gallery Tech Bull. 2005;26:71-87.

64. Philadelphia Museum of Art. IOD00367, Pigment Red 112 (PR112). In: Infrared and Raman Users Group spectral database. Philadelphia: Infrared and Raman Users Group; 2007. http://irug.org/jcamp-details?id=568. Accessed 20 Dec 2021.

65. Pronti L, Mazzitelli J-B, Bracciale MP, Massini Rosati L, Vieillescazes C, Santarelli ML, et al. Multi-technique characterisation of commercial alizarin-based lakes. Spectrochim Acta A. 2018;200:10-9. https://doi.org/ 10.1016/j.saa.2018.04.008.

66. Schweppe H, Winter J. Madder and alizarin. In: West FitzHugh E, editor. Artists' pigments: a handbook of their history and characteristics. Washington: National Gallery of Art; 1997. p. 112, 124, 131.

67. Gettens RJ, Feller RL, Chase WT. Vermilion and cinnabar. Stud Conserv. 1972;17(2):45-69. https://doi.org/10.1179/sic.1972.006.

68. Gettens RJ, Feller RL, Chase WT. Vermilion and cinnabar. In: Roy A, editor. Artists' pigments: a handbook of their history and characteristics. Washington: National Gallery of Art; 1993. p. 171.

69. Pause R, Neevel JG, van den Berg KJ, et al. Synthetic organic pigments in Talens oil paint 1920-1950 — the sase of vermillion imit. In: van den Berg KJ, Bonaduce I, Burnstock A, Ormsby B, Scharff M, Carlyle L, et al., editors. Conservation of modern oil paintings. Cham: Springer International Publishing; 2019. p. 109-18.

70. Sabatini F, Lluveras-Tenorio A, Degano I, Kuckova S, Krizova I, Colombini MP. A matrix-assisted laser desorption/ionization time-of-flight mass spectrometry method for the identification of anthraquinones: the case of historical lakes. J Am Soc Mass Spectrom. 2016;27(11):1824-34. https:// doi.org/10.1007/s13361-016-1471-4.

71. Chieli A, Sanyova J, Doherty B, Brunetti BG, Miliani C. Chromatographic and spectroscopic identification and recognition of ammoniacal 
cochineal dyes and pigments. Spectrochim Acta A. 2016;162:86-92. https://doi.org/10.1016/j.saa.2016.03.007.

72. Liu K. Trip to Bali. In: Siew S, editor. Liu Kang: essays on art and culture. Singapore: National Art Gallery; 2011. p. 57-62.

73. Kamarudin Z, Said I. Configuration of carved components and its layout patterns in Malay timber houses. ArchNet-IJAR. 2011;5(1):7-21.

74. Ju SR, Omar S, Ko YE. Modernization of the vernacular Malay house in Kampong Bharu, Kuala Lumpur. J Asian Archit Build Eng. 2012;1 1(1):95102. https://doi.org/10.3130/jaabe.11.95.
75. Rawanchaikun T. Nanyang 1950-65. Passage to Singaporean art. Fukuoka: Fukuoka Asian Art Museum; 2002. p. 10

\section{Publisher's Note}

Springer Nature remains neutral with regard to jurisdictional claims in published maps and institutional affiliations. 